Check for updates

Cite this: RSC Adv., 2020, 10, 20620

\title{
Synthetic non-classical luminescence generation by enhanced silica nanophotonics based on nano- bio-FRET
}

\author{
Carina Salinas, ${ }^{a}$ María Valeria Amé ${ }^{b}$ and A. Guillermo Bracamonte (iD *ac
}

Fluorescent silica nanoparticles (NPs- $\left.\left(\mathrm{SiO}_{2}-\mathrm{Fluo}\right)\right)$ were synthesized based on the classical Störber method for cyanobacteria labelling. Modified mono-coloured $\mathrm{SiO}_{2} \mathrm{NPs}$ with fluorescein $(\mathrm{Fl})$ and rhodamine $\mathrm{B}(\mathrm{RhB})$ were obtained (NPs- $\left(\mathrm{SiO}_{2}-\mathrm{Fl}\right)$ and $\mathrm{NPs}-\left(\mathrm{SiO}_{2}-\mathrm{RhB}\right)$ ). Moreover, multi-coloured $\mathrm{SiO}_{2} \mathrm{NPs}$, via the incorporation of both emitters (NPs- $\left(\mathrm{SiO}_{2}-\mathrm{RhB}-\mathrm{Fl}\right)$ ), were tuned for optimal emissions and the biodetection of cyanobacteria. NPs- $\left(\mathrm{SiO}_{2}-\mathrm{Fl}\right)$ and $\mathrm{NPs}-\left(\mathrm{SiO}_{2}-\mathrm{RhB}-\mathrm{Fl}\right)$ were optimized for detection via laser fluorescence microscopy and in-flow cytometry with laser excitation and fluorescence detection. By TEM, homogeneous $\mathrm{SiO}_{2} \mathrm{NPs}$ of $180.0 \mathrm{~nm}$ in diameter were recorded. These sizes were slightly increased due to the covalent linking incorporation of fluorescent dye emitters to $210.0 \mathrm{~nm}$ with monocoloured fluorescent modified amine-organosilanes, and to $340.0 \mathrm{~nm}$ in diameter with multi-coloured dye incorporation. NPs-( $\left.\mathrm{SiO}_{2}-\mathrm{Fluo}\right)$ showed variable emission depending on the dye emitter concentration, quantum yield and applied luminescent pathway. Thus, mono-coloured $\mathrm{NPs}-\left(\mathrm{SiO}_{2}-\mathrm{Fl}\right)$ and NPs- $\left(\mathrm{SiO}_{2}-\mathrm{RhB}\right)$ showed diminished emissions in comparison to multi-coloured $\mathrm{NPs}-\left(\mathrm{SiO}_{2}-\mathrm{RhB}-\right.$ $\mathrm{Fl}$ ). This enhancement was explained by fluorescence resonance energy transfer (FRET) between $\mathrm{Fl}$ as a fluorescent energy donor and RhB as an energy acceptor produced within the nanoarchitecture, produced only in the presence of both fluorophores with the appropriate laser excitation of the energy donor. The depositions of the nano-emitters on cyanobacteria by non-covalent interactions were observed by TEM and laser fluorescence microscopy. For multi-coloured NPs-( $\left.\mathrm{SiO}_{2}-\mathrm{RhB}-\mathrm{Fl}\right)$ labelling, bio-FRET was observed between the emission of the nano-labellers and the natural fluorophores from the cyanobacteria that quenched the emission of the whole nano-biostructure in comparison to monocoloured $\mathrm{NPs}-\left(\mathrm{SiO}_{2}-\mathrm{Fl}\right)$ labelling. This fact was explained and discussed in terms of different fluorescence energy transfer from the nanolabellers towards different natural chromophore coupling. In the presence of $\mathrm{NPs}-\left(\mathrm{SiO}_{2}-\mathrm{RhB}-\mathrm{Fl}\right)$ and $\mathrm{NPs}-\left(\mathrm{SiO}_{2}-\mathrm{RhB}\right)$, the emission was coupled with lower quantum yield chromophores; while upon the application of $\mathrm{NPs}-\left(\mathrm{SiO}_{2}-\mathrm{Fl}\right)$, it was coupled with higher quantum yield chromophores. In this manner, for enhanced luminescent nanoplatform tracking, the multi-coloured NPs- $\left(\mathrm{SiO}_{2}-\mathrm{RhB}-\mathrm{Fl}\right)$ showed improved properties; but more highly luminescent biosurfaces were generated with mono-coloured $\mathrm{NPs}-\left(\mathrm{SiO}_{2}-\mathrm{Fl}\right)$ that permitted faster cyanobacteria detection and counting by laser fluorescence microscopy, and by in-flow cytometry with laser excitation and fluorescence detection.

Received 31st March 2020

Accepted 15th May 2020

DOI: $10.1039 / \mathrm{dOra02939d}$

rsc.li/rsc-advances coupled to higher level of information collected from individual biostructures. In this manner the signal collected should transduce from the total biostructure surface to arrive at molecular event detection within the biostructure. For these reasons the advent of bioimaging, by different techniques and chemical approaches, is in progress with high impact on new advanced instrumentation and new products on the market available for researchers as well as to professionals from different fields. In addition new phenomena from physics coupled to chemical properties permit new research studies and developments.

In order to realize bioimaging, it could be applied different approaches, but it should be mentioned that fluorescence due 
to its intrinsic high sensitivity is widely used and well developed. However, it is still a challenge for targeted enhanced applications.

From the literature it could be mentioned tuning in vivo Gram positive and negative bacteria with red fluorescent dyes for imaging, at $650 \mathrm{~nm}$ emission wavelengths, ${ }^{1}$ where it was studied and overcame many aspects related to the specific incorporation of organic molecules within membranes and background signalling. Moreover, other strategies as applications of different luminescent nanoarchitectures should be highlighted. Examples are self-assembled quantum dots as fluorescence resonance energy transfer (FRET) donors in the presence of fluorescent modified saccharide membranes of Escherichia coli bacteria. ${ }^{2}$ Others are fluorescence energy transfer inhibition bioassays for cholera toxin based on galactosestabilized gold nanoparticles and amine-terminated quantum dots. ${ }^{3}$ In these examples, it was highlighted the importance of the main role of the control of energy transfer by light stimulation for biodetection applications. In addition studies related to high-energy electromagnetic fields generated from metallic surfaces within the near field at the nanoscale and their interactions with fluorescent molecules showed enhanced emissions named as metal enhanced fluorescence (MEF), ${ }^{4}$ which permitted new biolabelling approaches based on natural fluorescent molecular sensing within biomembranes in the presence of deposited silver nanoparticles at the right distance. ${ }^{5}$ In this manner, the importance of studying different energy pathways within biostructures via quantum experimental approaches was shown as well. Recently it was reported how energy transfer by photosynthetic proteins within bacteria produced modifications from the excited state of excitonic superpositions to the basal state with energy migration, suggesting the quantum role of non-classical energies in natural photosynthetic systems. ${ }^{6}$ If the focus is on nanomaterials for biolabelling applications, one should mention the use of biocompatible hybrid nanomaterials from different synthetic and natural sources as for example silica and gold nanomaterials with optical transparent ${ }^{7}$ and optically active properties respectively in addition to biocompatible properties that permit silica being considered as an inorganic collagen, ${ }^{8}$ and gold nanoparticles applied for laser-assisted therapy for controlled CRISPR delivery in vivo. ${ }^{9}$ In addition should be highlighted silica nanomaterials and applications based on nanophotonic luminescent nanoparticles with the incorporation of organic fluorescent dyes ${ }^{\mathbf{1 0}}$ within silica nanocomposites for biomedical imaging, ${ }^{11}$ multiple homogeneous immunoassays based on quantum dots-gold nanorods by FRET nanoplatforms, ${ }^{12}$ gold core-shell silica nanoparticles for biosensing ${ }^{13}$ by MEF, silica waveguides by resonant fluorescent core-shell nanoparticles by $\mathrm{MEF}^{\mathbf{1 4}}$ and drug delivery applications via a controlled silica porosity. ${ }^{15}$ So, silica has been widely applied and is still a key nanomaterial for nanophotonic developments. However, new biomaterials are being developed, for example based on controlled nano-aggregated biomolecules with fluorescent properties for bioimaging applications. ${ }^{\mathbf{1 6}}$

In particular for this research study, our interest was in cyanobacteria due to their environmental implications and optical active properties. Cyanobacteria or blue-green algae are the dominant phytoplankton group in eutrophic freshwater bodies worldwide. Moreover, climate change has contributed to increases in cyanobacteria occurrence in surface waters, and the risk of harmful algae blooms. ${ }^{17}$ Therefore, many countries or jurisdictions have implemented specific water quality regulations to protect public health and safety. Drinking water quality guidelines related to cyanobacteria are based on maximum acceptable concentrations of toxins (e.g., microcystin-LR) in treated water (e.g., $1.0 \mu \mathrm{g} \mathrm{L}^{-1}$ proposed by WHO in 1999) or high levels of cyanobacterial cells (e.g., $\geq 100000$ cells per $\mathrm{mL}$ ) in water supplies (WHO, 2011). ${ }^{\mathbf{1 8}}$ Despite the time required for identification, confirmation, and enumeration of cyanobacterial cells, direct microscopic enumeration is the simplest and most cost-effective method still used. In natural samples, this method involves some limitations such as the weak contrast of cells against the background, high species diversity, variable morphology of individual cells, and complexity of cell aggregates or units (colonies, entangled filaments etc.).

Indirect quantification methods also have been developed to estimate cyanobacterial cell concentrations in water, such as flow cytometry, antibody-mediated immunofluorescence microscopy assays, PCR-fluorescent fragment detection, qPCR molecular probes using sandwich hybridization, and in situ fluorescence. However, all of them have some drawbacks, and cost-effective, fast, and reliable cyanobacterial cell identification and enumeration methods are thus much needed. ${ }^{19}$

Therefore, imaging-based enumeration methods appear to be promising for rapid and low-cost water quality monitoring of cyanobacteria, and fluorescent silica nanoparticles could be a means to improve the detection limits and sensitivity of these methods.

Moreover, these types of bacteria were evaluated as optically active biostructures ${ }^{20}$ that interact by non-classical light pathways with luminescent nanoplatforms for potential biotechnological applications ${ }^{21}$ as well.

For these reasons, our interest was focused in the design and synthesis of tunable hybrid nanomaterials based on fluorescent silica nanoparticles with enhanced properties based on FRET for biolabelling applications.

In this manner, for this research communication fluorescent emission properties were tuned by the incorporation of well overlapped spectroscopic properties and optimal quantum yields from molecular donor-acceptor pairs within silica nanoparticles. These nano-emitters were applied for noncovalent cyanobacteria labelling and detection by enhanced fluorescence imaging recorded with laser fluorescence microscopy. Then, evaluation was by in-flow cytometry with nanobiostructure detection and counting with laser excitation and fluorescence detection.

\section{Experimental}

\subsection{Apparatus}

An Olympus confocal laser scanning microscope, FluoView FV1000, was used for fluorescence microscopy imaging and for bright-field confocal microscopy. 


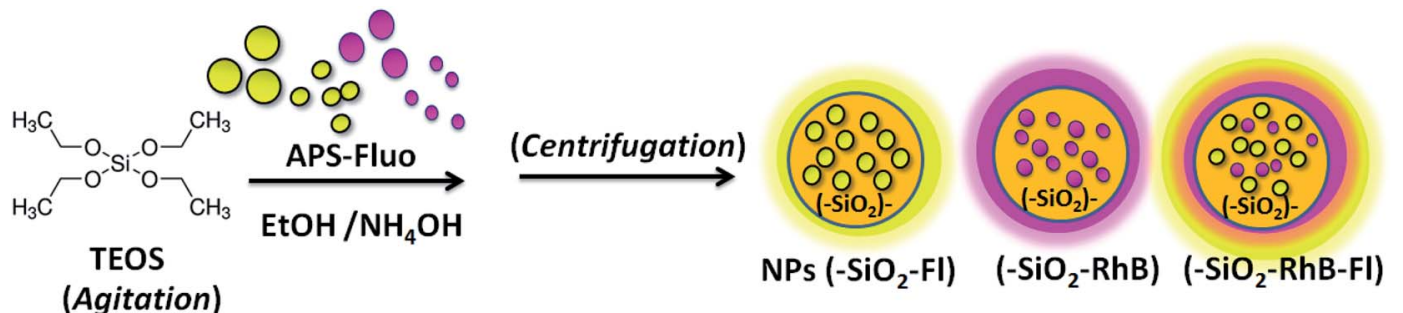

Scheme 1 A schematic diagram showing the synthesis of fluorescent silica nanoparticles $\left(\mathrm{NPs}-\left(\mathrm{SiO}_{2}-\mathrm{Fluo}\right)\right)$ via the covalent linking of fluorescein $(\mathrm{Fl})$ and rhodamine $\mathrm{B}(\mathrm{RhB})$ to obtain mono-coloured $\mathrm{NPs}-\left(\mathrm{SiO}_{2}-\mathrm{Fl}\right)$ and $\mathrm{NPs}-\left(\mathrm{SiO}_{2}-\mathrm{RhB}\right)$ and multi-coloured $\mathrm{NPs}-\left(\mathrm{SiO}{ }_{2}-\mathrm{RhB}-\mathrm{Fl}\right)$.

Transmission electron microscopy (TEM), JEM-1230, JEOL, with an operating voltage of $200 \mathrm{kV}$, was used for determination of nanoparticle size.

UV-visible and spectrofluorimetric determinations were carried out with a Varian UV-50 Cary 50 Conc. and a CaryEclipse respectively. Lifetime measurements were done with a PicoQuant FluoTime 2000.

The flow cytometer was from BD, model FACSCalibur, with laser excitation at $488.0 \mathrm{~nm}$ and $555.0 \mathrm{~nm}$ with standard filters at 533/30 and 585/40 for Alexa Fluor 488-A and AF5555-a.

An ultrasonic bath (Branson 2510) was used for the dispersion of the reagents and colloids. Centrifugation was done using an Eppendorf Centrifuge 5804 (range 7500-8000 rpm).

Data analysis was performed with Origin (Scientific Graph system), version 8 .

\subsection{Reagents}

Water was obtained using a Millipore apparatus. Other reagents were rhodamine B (RhB) and fluorescein (Fl) (99\% purity, SigmaAldrich), tetraethyl orthosilicate (TEOS) (98\%, Sigma-Aldrich), ethanol (Sintorgan, HPLC grade), 3-(aminopropyl)triethoxysilane (APS) (98\%, Sigma-Aldrich), $N$-hydroxysuccinimide (NHS) and $N$ (3-dimethylaminopropyl)- $N$-ethylcarbodiimide hydrochloride (EDC) (98\%, Sigma-Aldrich) and sodium cyanide (95\%, SigmaAldrich).

Ultra-filtrated and deionized water was obtained using a Millipore apparatus.

Micrometer multicolor beads from BD Company were used as control particles for in-flow cytometry.

The wild population of Microcystis aeruginosa was concentrated from an atoxic bloom collected in San Roque water reservoir (Cordoba, Argentina).

\subsection{General procedures}

Silica nanoparticles were synthesized based on the classical Störber method..$^{22,23}$ In order to do that, the TEOS concentration was adjusted by variable volume addition of $\mu \mathrm{L}$ aliquots into basic ethanol solution $(\mathrm{pH}=9.00)$ adjusted with concentrated ammonium hydroxide. For the TEOS reaction, variable $\mu \mathrm{L}$ aliquots of TEOS were added, maintaining constant the ratios of reagents as described in the following. The ratio of TEOS/ ethanol $/ \mathrm{H}_{2} \mathrm{O} / \mathrm{NH}_{4} \mathrm{OH}$ was $150 / 2300 / 80 / 620$. For example, for a typical synthesis of varied sizes of silica nanoparticles, 20.0, 40.0 and $80.0 \mu \mathrm{L}$ were added of a concentrated solution of TEOS
$=0.215 \pm 0.03 \mathrm{M}$ in $2.5 \mathrm{~mL}$ final volume. In this manner were obtained concentrated colloidal dispersions of silica nanoparticles of varied sizes. The average sizes of nanoparticles were $200.0 \mathrm{~nm}, 240.0 \mathrm{~nm}$, and $380.0 \mathrm{~nm}$, respectively. The errors associated with the determinations of sizes were in general average values of $\pm 5 \mathrm{~nm}$ for smaller sizes (200.0-300.0 nm), and $\pm 10 \mathrm{~nm}$ for larger sized nanoparticles (350.0-450.0 nm).

Fluorescent silica nanoparticles were obtained by incorporation into the described silica nanoparticle synthesis fluorophores covalently bonded to modified organosilanes dissolved in ethanol (Scheme 1). The covalent linking of Fl and RhB was done by activation of their carboxylic groups with NHS/ EDC and nucleophilic attack from the amine group of APS. ${ }^{13}$ For a typical reaction, $2 \mathrm{mg}$ of $\mathrm{RhB}$ or $\mathrm{Fl}$ was added in the presence of 10 times higher concentrated APS and NHS/EDC in $2.0 \mathrm{~mL}$ total volume of ethanol. Thus, APS-Fl and APS-RhB were obtained.

The silica nanoparticles were centrifuged at $8500 \mathrm{rpm}$ and redispersed in anhydrous ethanol.

The concentrations of fluorophores loaded within the nanoparticles were determined by static fluorescence. These values were obtained from the difference of the known APSfluorophore concentration added and the concentration of the non-incorporated APS-fluorophores collected from the supernatant of the colloidal dispersion media of the synthesis. So, calibration curves were made for the concentration of APSfluorophores used for the synthesis of the different fluorescent silica nanoparticles. At the same time the determined values were corroborated by absorption measurements. Moreover, additional controls for dye content within coloured silica nanoparticles were developed by disintegrating the nanostructures in strong $(\mathrm{pH}=1)$ acid media and sonication for a period of $4 \mathrm{~h}$, and then quantifying the respective fluorescent dyes incorporated.

After the synthesis of the fluorescent silica nanoparticles, their emission was controlled to regular levels before use. The control was done by static fluorescence and laser fluorescence microscopy. To do that, the samples were centrifuged and controlled the presence of nanoparticles in the supernatant by dynamic light scattering (DLS). Thus was evaluated the fluorophore leakage from the cleaned supernatant, and the standard emission intensity of nanoparticles from the re-suspended sample. No leakage was recorded for the samples used in the different experiments. And the percentage of variation within 

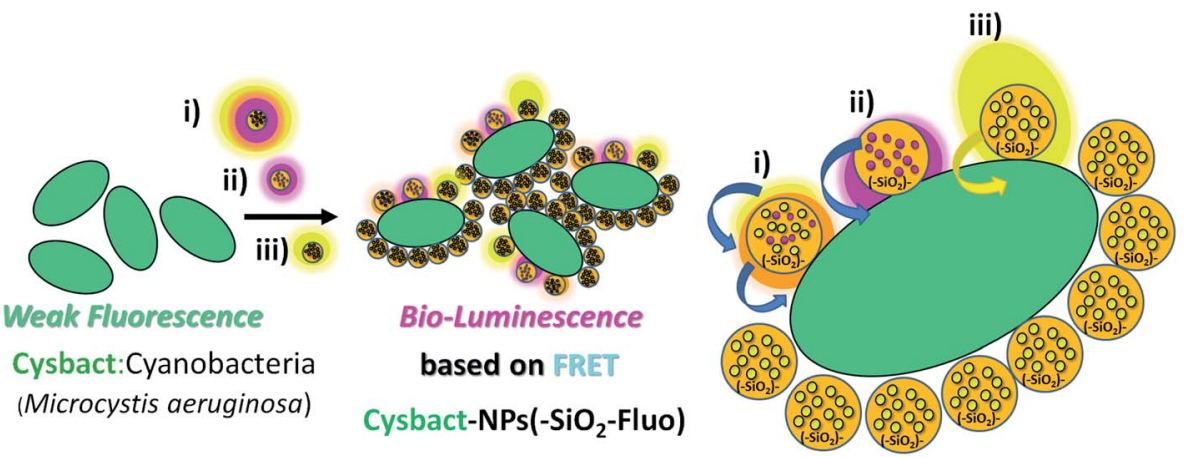

Scheme 2 A schematic diagram showing the biolabelling of cyanobacteria (cysbact) with fluorescent mono-coloured $\mathrm{SiO}_{2}-\mathrm{Fl}$ and $\mathrm{SiO}{ }_{2}-\mathrm{RhB}$ NPs and multi-coloured $\mathrm{SiO}_{2}-\mathrm{RhB}-\mathrm{Fl} \mathrm{NPs}$, by non-covalent interactions.

different measurements for the same samples was below $\pm 5 \%$. In this manner, were investigated samples with low background emissions determined by laser fluorescence microscopy.

Fluorescence emission spectra were measured with an excitation wavelength equal to the wavelength of maximum absorption of the fluorescent dyes $\left(\lambda_{\mathrm{exc}}=480.0\right.$ and $539.0 \mathrm{~nm}$ for $\mathrm{Fl}$ and $\mathrm{RhB}$ respectively). In order to confirm that the maximal emission fluorescence was measured in these conditions, the excitation wavelength was evaluated by measuring 3D fluorescence emission spectra. For emission and excitation fluorescence spectra, the excitation and emission bandwidths were set at $10 \mathrm{~nm}$. The PMT gain was medium. All the measurements were performed at $(25.0 \pm 0.1){ }^{\circ} \mathrm{C}$, with the temperature of the cell compartment being controlled with a Haake K10 circulator under continuous stirring.

The fluorescence lifetime decay measurements of the fluorescent silica nanoparticles were performed in ethanol.

The cyanobacteria bloom Microcystis aeruginosa was concentrated from a sample collected in San Roque water reservoir (Cordoba, Argentina). Cell counts of Microcystis aeruginosa were performed with a standard optical microscope using a haemocytometer and then followed by measuring optical density (OD) at $600 \mathrm{~nm}$ (OD of 0.1 corresponds to a concentration of $10^{8}$ cells per $\mathrm{mL}$ ). The conservation of these samples was performed in diluted $(1 / 10)$ phosphate-buffered saline (PBS buffer) aqueous solution used for typical DNA hybridization assays.

From this concentrated colloidal dispersion of bacteria, dilutions were done at intermediate and diluted concentration levels ( 0.2 and $0.05 \mathrm{OD}$ values at $600 \mathrm{~nm}$ respectively). Each inoculum was examined with the microscope to confirm its composition and the dominance of Microcystis aeruginosa within the sample $(>99 \%$ cells counted correspond to these cyanobacteria).

For cyanobacteria-nanoparticle interaction, a dispersion of cells was prepared from the bloom sample of Microcystis aeruginosa. The bacterial concentrations were determined by measuring OD at $600 \mathrm{~nm}$ at intervals of $30 \mathrm{~min}$ (OD of 0.1 corresponds to a concentration of $10^{8}$ cells per $\mathrm{mL}$ ). In this manner, from a concentrated dispersion of cyanobacteria in aqueous media, variable dilutions were prepared depending on the number of biostructures intended to be determined by the optical microscopy techniques used. Thus, by bright-field confocal microscopy as control, from individual bacteria were obtained micro-aggregates of bacteria. For fluorescent labelling, the dispersions were in contact with variable additions of $\mu \mathrm{L}$ aliquots of concentrated fluorescent silica nanoparticles for a $4 \mathrm{~h}$ period of time (Scheme 2). For typical cell labelling, $0.5 \mathrm{~mL}$ of concentrated sample in water was added into $2.0 \mathrm{~mL}$ of colloidal dispersion (total volume of $2.5 \mathrm{~mL}$ ). The concentrations of fluorescent nanoparticles as nanolabellers were within the interval of $9 \times 10^{8}$ to $10^{10} \mathrm{NPs}$ per $\mathrm{mL}$ depending on the cyanobacterial bloom concentration used.

After that the samples were observed by laser fluorescence microscopy with a minimal volume added ( 1 drop of $20 \mu \mathrm{L}$ ) on a microscope glass slide (covered after addition with a coverglass). For this technique was applied laser excitation at 488.0, 543.0 and $555.0 \mathrm{~nm}$. The emission filter bands were placed in the interval of emission wavelengths of 510-625 nm and 575$650 \mathrm{~nm}$ for $488.0 \mathrm{~nm}$ laser excitation, and within the interval of $575-650 \mathrm{~nm}$ for $543.0 \mathrm{~nm}$ and $555.5 \mathrm{~nm}$ laser excitations.

For the in-flow cytometry analysis, contour plots of sidescattered light (SSC; proportional to cell granularity or internal complexity) vs. forward-scattered light (FSC; proportional to cell-surface area or size) were used to characterize distributions of fluorescent event detections. Laser excitations at $488.0 \mathrm{~nm}$ and $555.0 \mathrm{~nm}$ with emission filters of $530 / 30 \mathrm{~nm}$ and $585 / 42 \mathrm{~nm}$ were used.

The nano-imaging was recorded by variable look-up table image edition (LUT) of brightness and contrast parameters. For bio- and nano-imaging, green, red-green and fire LUT were applied, depending on the degree of detail tracked. For images generated with higher contrast with the background, green and fire LUT were used; while for differentiated intensities recording, red-green LUT was used. For the image edition, the background signal was subtracted that never overcame $10 \%$ of the higher intensity collected.

\section{Results and discussion}

\subsection{Characterization of mono-coloured and multi-coloured fluorescent silica nanoparticles}

Silica nanoparticles were obtained by the Störber method with varied diameters depending on the added TEOS concentrations. 

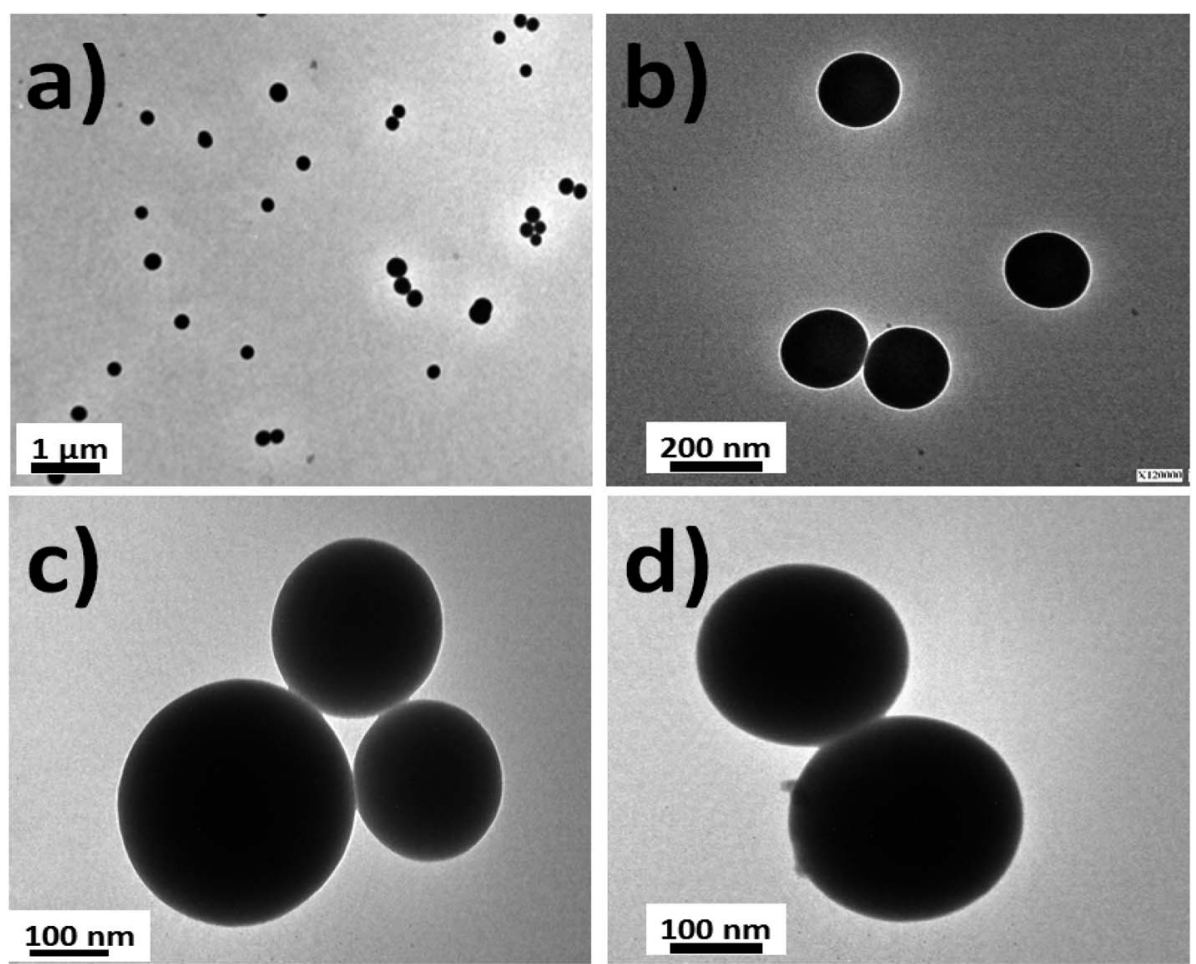

Fig. 1 TEM images of silica nanoparticles: (a) the homogeneous distribution of silica nanoparticles; (b) individual silica nanoparticles of 180$200 \mathrm{~nm}$ in diameter; (c) silica nanoparticle trimers; and (d) the dimeric nanoparticle distribution.

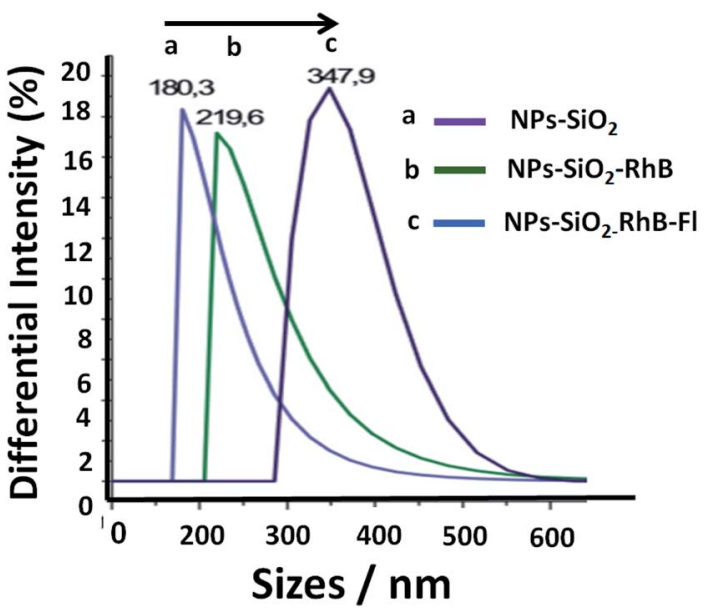

Fig. 2 Distribution of sizes in the colloidal dispersion of silica nanoparticles from DLS: (a) non-fluorescent silica nanoparticles (NPs$\mathrm{SiO}_{2}$ ), (b) mono-coloured silica nanoparticles with rhodamine B (NPs$\mathrm{SiO}_{2}-\mathrm{RhB}$ ) or fluorescein (NPs-SiO $2-\mathrm{Fl}$ ), and (c) multi-coloured fluorescent silica nanoparticles (NPs-SiO $-\mathrm{RhB}-\mathrm{Fl}$ ). The concentrations incorporated within the silica nanoparticles were 0.39 and 0.27 $\mu \mathrm{M}$ for $[\mathrm{RhB}]$ and $[\mathrm{Fl}]$, respectively.

Sizes of 380.0, 250.0 and $200.0 \mathrm{~nm}$ were observed by TEM. From all batches of colloidal dispersions were observed homogeneous silica nanoparticles (Fig. 1a), with well-defined spherical shapes (Fig. 1b) accompanied by small trimer and dimer formations (Fig. 1c and d). The addition of the fluorescent dyes was done by their conjugation with APS for incorporation within the polymerized TEOS organosilane by covalent linking.

The fluorescent hybrid nanoarchitectures produced increased in size in the interval of 10 to $40 \%$ depending on the added conjugated fluorophore concentrations. For example, silica nanoparticles of 180-200 $\mathrm{nm}$ ranges of diameters were incorporated with $[\mathrm{RhB}]$ and $[\mathrm{Fl}]$ of 0.39 and $0.27 \mu \mathrm{M}$ respectively, which produced increased sizes of $20 \%$ for monocoloured to $40 \%$ for multi-coloured nanoparticles (Fig. 2).

Moreover, the one distribution of well-shaped Gaussians recorded from these nanoparticles showed the good dispersibility in ethanol as well as in aqueous colloidal dispersions. In order to verify the stability of the obtained nanoparticles, different measurements were recorded within a 10 minute period of time. Thus, the intensities and sizes of nanoparticles were stable in the mentioned period of time. For longer periods of time the intensities diminished due to the reduced number of detected nanoparticles. However, it should be highlighted the fast dispersibility of these samples by just shaking them. The zeta-potential measurements were in the interval of -20 to $30 \mathrm{mV}$. These measurements correlated with typical values from well-dispersible free gold and silver coresilica shell nanoparticles as well., ${ }^{\mathbf{4 , 2}}$

Moreover, the sizes determined by DLS correlated with determinations by TEM images (Fig. 3). Moreover, it should be mentioned that the addition of the fluorescent dyes did not modify the original spherical shapes of the different hybrid nanoparticles. For NPs-SiO ${ }_{2}-\mathrm{RhB}-\mathrm{Fl}$, sizes within the 330- 

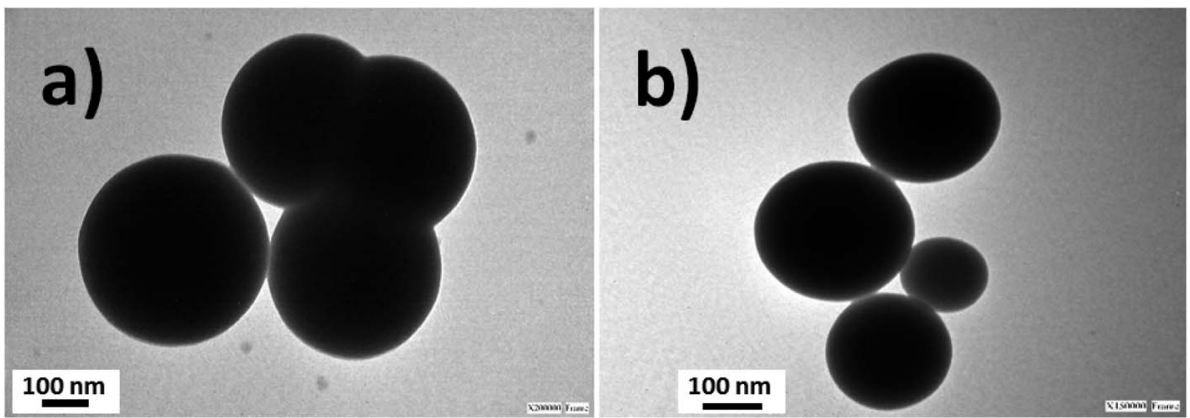

Fig. 3 TEM images of fluorescent silica nanoparticles: (a) multi-coloured fluorescent silica nanoparticles $\left(\mathrm{NPs}-\mathrm{SiO}{ }_{2}-\mathrm{RhB}-\mathrm{Fl}\right)$. The range of diameters is $330-350 \mathrm{~nm}$; (b) mono-coloured silica nanoparticles with rhodamine $\mathrm{B}\left(\mathrm{NPs}-\mathrm{SiO}_{2}-\mathrm{RhB}\right)$ or fluorescein $\left(\mathrm{NPs}-\mathrm{SiO}{ }_{2}-\mathrm{Fl}\right)$. The range of diameters is $230-240 \mathrm{~nm}$.

$350 \mathrm{~nm}$ range were recorded; while for $\mathrm{NPs}_{-} \mathrm{SiO}_{2}-\mathrm{RhB}$ and NPs$\mathrm{SiO}_{2}-\mathrm{Fl}$, average values were within $230-240 \mathrm{~nm}$.

Then by laser fluorescence microscopy, the nanoparticles obtained were evaluated. In this manner were recorded strong variable emissions from fluorescent nanoparticles with variable dimensions depending on the fluorophores incorporated and the emission pathways involved. From fluorescent silica nanoparticles modified with $\mathrm{Fl}\left(\mathrm{SiO}_{2}-\mathrm{Fl}\right)$ were recorded strong emission intensities from reduced sizes close to individual nanoparticle dimensions determined by TEM and DLS. Moreover NPs- $\left(\mathrm{SiO}_{2}-\mathrm{Fl}\right)$ nanoparticles showed good dispersibility and homogeneous nanostructures were detected (Fig. 4a); however more enhanced fluorescent nanoparticle detections were recorded from multi-coloured fluorescent silica nanoparticles (Fig. 4b).

About the stability and well-dispersible characteristics of the nanoparticles obtained within colloidal dispersions, it should be mentioned that the re-dispersion of decanted nanoparticles was done easily by simply manual shaking. So, for example, a fast re-dispersion of decanted nanoparticles in glass vials with a clear transparent and limpid solution was modified to bright yellow-orange colloidal dispersions for $\mathrm{NPs}-\left(\mathrm{SiO}_{2}-\mathrm{RhB}-\mathrm{Fl}\right)$, yellow for NPs-( $\left.\mathrm{SiO}_{2}-\mathrm{Fl}\right)$, and purple for $\mathrm{NPs}-\left(\mathrm{SiO}_{2}-\mathrm{RhB}\right)$ nanoparticles. Moreover, this phenomenon was observed as

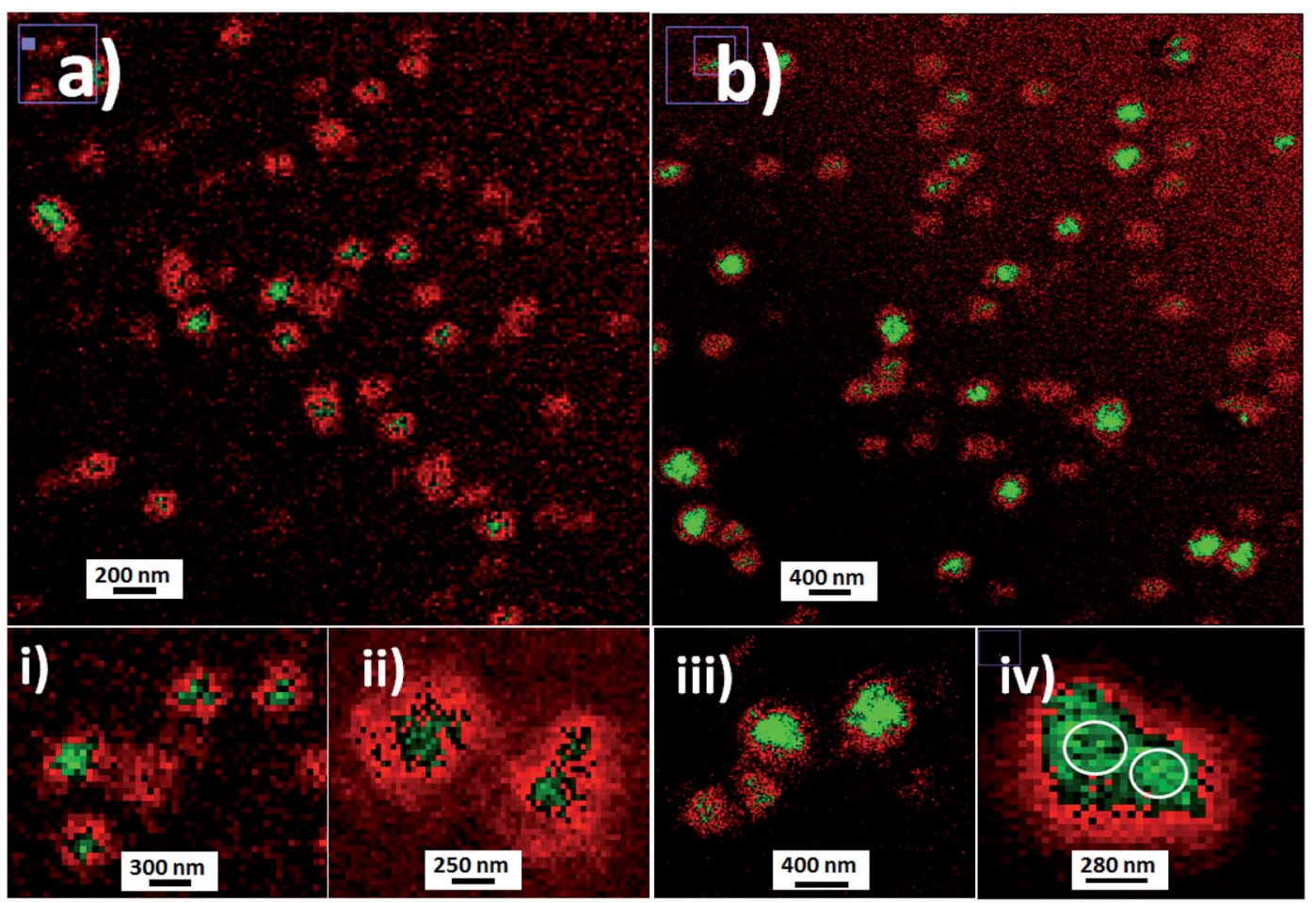

Fig. 4 Laser fluorescence microscopy images of fluorescent silica nanoparticles: (a) fluorescein (Fl) mono-coloured silica nanoparticles (SiO ${ }_{2}-$ Fl) $180 \mathrm{~nm}$ in diameter; (b) modified multi-coloured silica nanoparticles with the incorporation of Fl as a fluorescent energy donor and rhodamine $\mathrm{B}(\mathrm{RhB})$ as a resonant energy acceptor. Inset images: (i) and (ii) zoomed images of individual $\mathrm{SiO}_{2}-\mathrm{Fl}$ nanoparticles; (iii) and (iv) zoomed images of individual and dimeric $\mathrm{SiO}_{2}-\mathrm{RhB}-\mathrm{Fl}$ nanoparticles. Image edition with red-green color LUT. 
well by a change of opalescence from non-coloured silica nanoparticles.

The NPs- $\left(\mathrm{SiO}_{2}-\mathrm{Fl}\right)$ emission intensities showed bright and clear dots at $225.0 \mathrm{~nm}$ (inset (i) in Fig. 4). These nanoparticles produced a strong green fluorescent core surrounded with gradually diminished red fluorescence intensities (inset (ii) in Fig. 4) from dual-coloured red-green LUT image edition. However their intensities were lower than those of multicoloured silica nanoparticles with the incorporation of $\mathrm{RhB}$ and $\mathrm{Fl}\left(\mathrm{SiO}_{2}-\mathrm{RhB}-\mathrm{Fl}\right)$ (inset (iii) in Fig. 4). The multi-coloured NPs- $\left(\mathrm{SiO}_{2}-\mathrm{RhB}-\mathrm{Fl}\right)$ nanoparticles showed increased emissions of at least $35 \%$ accompanied by the generation of more enhanced fluorescent surfaces (inset (iv) of Fig. 4) in comparison to mono-coloured silica nanoparticles. The enhanced emitter surface core green highlight generated from multicoloured $\mathrm{NPs}-\left(\mathrm{SiO}_{2}-\mathrm{RhB}-\mathrm{Fl}\right)$ nanoparticles was explained by an improved fluorescence energy routing through the 3D silica nanostructure after interaction with the laser beam. In this manner were recorded higher emission intensities from more highly luminescent surfaces that generated bigger sizes of nanoparticles recorded by laser fluorescence microscopy (Fig. 4) than by TEM (Fig. 3).

Moreover, it should be mentioned that by single fluorescence nanoparticle analysis, the mono-coloured and multicoloured fluorescent nanoparticles showed homogeneous distributions of emission intensities as it was previously described. For this reason, at this point it should be clarified that the observed emission differences from the nanoparticles within colloidal dispersions (Fig. 4a and b) were attributed to nanoparticles randomly detected in Brownian motion in different planes and deep within a confined $\mu \mathrm{L}$-volume drop added on the glass microscope slide.

Moreover, it should be highlighted that the distributions of dimeric $\mathrm{SiO}_{2}$ nanoparticles based on non-covalent interactions previously mentioned (insets (iii) and (i) of Fig. 4) were explained by an optimal ratio of sizes and interaction strength. Due to the chemistry involved in the developed silica nanoparticles, the contributing forces were polar non-covalent interactions from the hydroxyl groups of silanol accompanied as well by attractive van der Waals interactions. These noncovalent interactions generated from nano-surfaces could be explained by Hamaker constants. ${ }^{25,26}$ The Hamaker constant considers the ratio of non-covalent interaction force and the available nano-surface in contact. ${ }^{27}$ In this manner, for example, were reported forces between dimers of larger sized polystyrene beads in the range between 0.3 and $50 \mathrm{pN}$ in the presence of controlled ionic strength. ${ }^{28}$ Thus, the higher frequency of dimeric forms of the silica nanoparticles obtained by us was explained as due to an optimal ratio of available surface and forces for intermediate particle sizes of 200-300 nm, and not just obtained by Brownian motion and encountering. This fact prompted our interest to study potential applications of dimeric forms by chemical modification of the nano-surfaces with short molecular spacers ${ }^{29-31}$ for non-classical light generation ${ }^{32}$ and nano-resolution. ${ }^{33}$

In addition, the enhanced surfaces accompanied by higher emission properties from $\mathrm{SiO}_{2}-\mathrm{RhB}-\mathrm{Fl}$ nanoparticles were

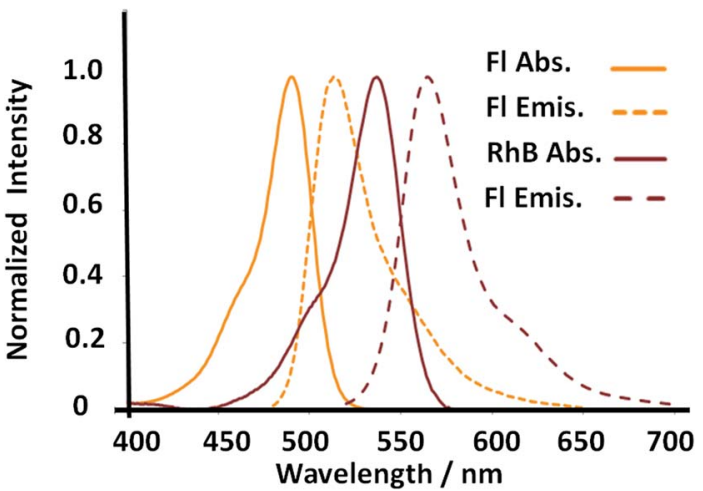

Fig. 5 Absorption and fluorescence emission properties of the donor and acceptor dyes incorporated within multicolor gold core-shell nanoparticles.

explained by FRET. ${ }^{34}$ Both fluorophores showed well overlapped spectroscopic properties from the emission of the energy donor (Fl) to the absorption of the energy acceptor (RhB) (Fig. 5). In addition, for the fluorescent energy donor ${ }^{35}$ were reported three times higher quantum yields than for the energy acceptor. ${ }^{36}$ This enhancement occurred only when the samples were excited at $488.0 \mathrm{~nm}$ that corresponded to the maximal absorption of $\mathrm{Fl}$ as fluorescent energy donor. While for $543.0 \mathrm{~nm}$ and $555.0 \mathrm{~nm}$ laser excitations, for only the energy acceptor RhB stimulation, diminished emissions were recorded in comparison to $488.0 \mathrm{~nm}$ laser excitation. Moreover, controls of monocoloured silica nanoparticles showed drastic reductions of their emissions in comparison to multi-coloured nanoparticles. These phenomena via FRET pathways were previously studied by us. ${ }^{37}$

The observations achieved by laser fluorescence microscopy were recorded with emission filters in the interval of emission wavelengths of 510-625 $\mathrm{nm}$ for $488.0 \mathrm{~nm}$ laser excitation to record the complete emission band of both fluorophores considering all the fluorescence emission phenomena as individual fluorophore emission and coupled phenomena via FRET. Similar observations were recorded when the interval of the emission filters was changed to longer emission wavelengths, as 575-650 $\mathrm{nm}$ (with $488.0 \mathrm{~nm}$ laser excitation), to diminish the contribution of the $\mathrm{Fl}$ fluorescent reporter and increase the contribution of the emission from the FRET pathway. However, for $543.0 \mathrm{~nm}$ and $555.5 \mathrm{~nm}$ laser excitation of only the RhB fluorescent reporter with longer interval of emission window, at 575-650 nm, their emission intensities were drastically diminished in comparison to $488.0 \mathrm{~nm}$ laser excitation.

In order to tune the optimal emissions considering the wellknown quenching by intermolecular energy homo-transfer for $\mathrm{Fl}^{38}$ and $\mathrm{RhB},{ }^{39}$ the concentration of both fluorescent laser dyes was varied. Then in optimal concentration conditions for maximal emissions, and neglecting reduction of emission by quenching in confined volumes, the ratio of concentrations between $\mathrm{RhB}$ and $\mathrm{Fl}$ (ratio of $\mathrm{RhB}: \mathrm{Fl}$ ) was varied. In this manner with optimal excitation of $\mathrm{Fl}$ as fluorescent energy donor, variable fluorescence emission was recorded depending 


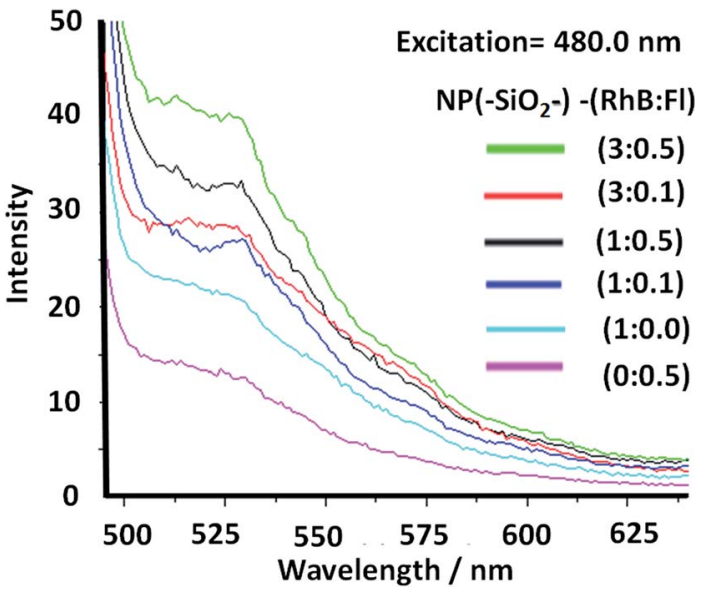

Fig. 6 Static fluorescence emission of multi-coloured silica nanoparticles with different ratios of rhodamine $\mathrm{B}(\mathrm{RhB})$ and fluorescein $(\mathrm{Fl})$ concentrations ( $\left.\mathrm{NP}\left(\mathrm{SiO}_{2}-\right)-\mathrm{RhB}: \mathrm{Fl}\right)$. The ratio $1: 1$ corresponds to 1.0 $\mu \mathrm{M}$. The excitation wavelength, applied at $480.0 \mathrm{~nm}$, corresponds to the optimal excitation of $\mathrm{Fl}$ as a fluorescent energy donor reporter.

on RhB : Fl ratio (Fig. 6) within the interval of emission wavelengths of $\mathrm{Fl}$ and $\mathrm{RhB}$. From a $\mathrm{RhB}: \mathrm{Fl}$ ratio $=1: 0$ with monocoloured $\mathrm{SiO}_{2}-\mathrm{RhB}$ NPs to $\mathrm{RhB}: \mathrm{Fl}$ ratio $=1: 0.1$ and $1: 05$ with multi-coloured $\mathrm{SiO}_{2}-\mathrm{RhB}-\mathrm{Fl} \mathrm{NPs}$, higher emissions were recorded with increasing concentrations of $\mathrm{Fl}$ than for monocoloured $\mathrm{SiO}_{2} \mathrm{NP}$ controls. As reference value the ratio $1: 1$ corresponded to the incorporation of a total dye concentration of $1.00 \pm 0.04 \mu \mathrm{M}$. In this manner, multi-coloured silica nanoparticles with a ratio of $\mathrm{RhB}: \mathrm{Fl}=1$ were incorporated with concentrations of each component in the interval of $0.4-0.6 \mu \mathrm{M}$.

From the fluorescence measurements the ratio of emissions was evaluated within different intervals of wavelengths attributed to $\mathrm{RhB}$ and $\mathrm{Fl}$ at the different ratio of concentrations of both fluorophores incorporated.

In this manner, the ratios of intensities between the emissions of $\mathrm{Fl}$ and $\mathrm{RhB}$ within the $\mathrm{SiO}_{2}-\mathrm{RhB}-\mathrm{Fl} \mathrm{NPs}$ were $\mathrm{Fl} / \mathrm{Fl}_{\text {ref. }}=$ 1.7 and 2.3 for $\mathrm{RhB}: \mathrm{Fl}$ ratio $=1: 0.1$ and $1: 05$ respectively. While the ratios $\mathrm{RhB} / \mathrm{RhB}_{\text {ref. }}$ were 1.1 and 1.5 (Table 1). As could

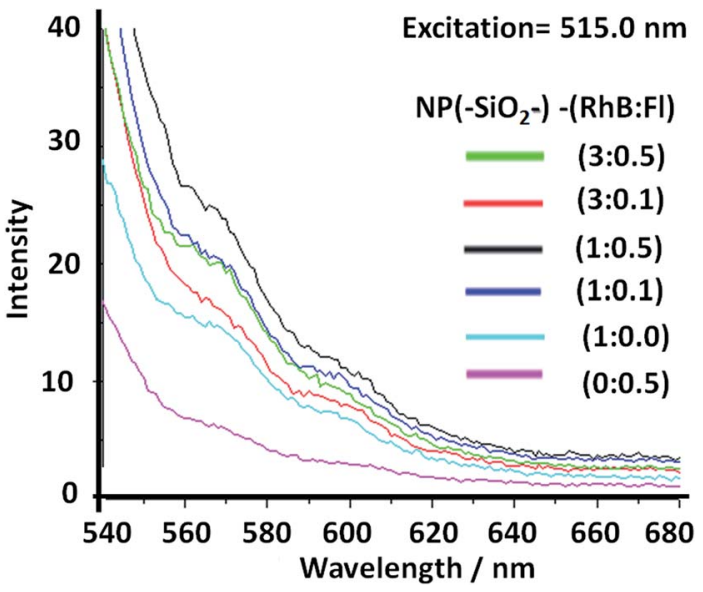

Fig. 7 Static fluorescence emission from multi-coloured silica nanoparticles with different ratios of rhodamine $B(\mathrm{RhB})$ and fluorescein (Fl) concentrations. The ratio $1: 1$ corresponds to $1.0 \mu \mathrm{M}$. The excitation wavelength applied was $515.0 \mathrm{~nm}$, which corresponds to improved $\mathrm{RhB}$ as a fluorescent energy acceptor and partially diminished excitation of $\mathrm{Fl}$ as a fluorescent energy acceptor.

be observed from these results, both emissions bands had higher emission than for mono-coloured $\mathrm{SiO}_{2} \mathrm{NPs}$.

Moreover, for RhB : Fl ratios of $3: 0.1$ and $3: 0.5$, ratios of intensities between the emissions of $\mathrm{Fl}$ in the presence and absence of $\mathrm{RhB}\left(\mathrm{Fl} / \mathrm{Fl}_{\mathrm{ref}}\right)$ of 3.0 and 1.9 respectively were observed (Table 1). So, the tendency showed a diminution and opposite direction in comparison to lower concentration of RhB as energy acceptor. This trend was produced by the quenching. effect from dimeric species of both fluorophores at higher concentrations of RhB and Fl.

In this way should be highlighted the ratio of intensities between $\mathrm{RhB}$ and $\mathrm{Fl}(\mathrm{RhB} / \mathrm{Fl})$ emission bands increasing the $\mathrm{RhB}$ concentrations from $\mathrm{RhB}: \mathrm{Fl}=1.0: 0.5$ to $3.0: 0.5$, and $1.0: 0.1$ to $3.0: 0.1$ that generated a reduction of their emissions (Table 1). So, considering only increasing the concentration of RhB as energy acceptor, the emissions were reduced caused by homo-transfer and quenching. It is known that for higher concentrations of these dyes, homo-transfer was

Table 1 Fluorescence emission band ratios of multi-coloured and mono-coloured silica nanoparticles

\begin{tabular}{|c|c|c|c|c|}
\hline \multirow[b]{2}{*}{$\mathrm{SiO}_{2} \mathrm{NPs}^{a}$} & \multirow[b]{2}{*}{ Ratio $[\mathrm{RhB}] /[\mathrm{Fl}]^{b}$} & \multicolumn{3}{|c|}{ 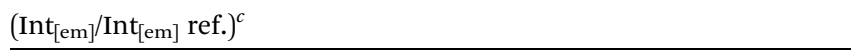 } \\
\hline & & $\left(\mathrm{Fl} / \mathrm{Fl}_{\text {ref. }}\right)$ & (RhB/RhB ref. $)$ & $(\mathrm{RhB} / \mathrm{Fl})$ \\
\hline \multirow[t]{4}{*}{$\mathrm{NP}\left(\mathrm{SiO}_{2^{-}}\right)-\mathrm{RhB}: \mathrm{Fl}^{d}$} & $3.0: 0.5$ & 1.9 & 1.2 & 0.9 \\
\hline & $3.0: 0.1$ & 3.0 & 1.7 & 0.7 \\
\hline & $1.0: 0.5$ & 2.3 & 1.5 & 1.0 \\
\hline & $1.0: 0.1$ & 1.7 & 1.1 & 1.0 \\
\hline $\mathrm{NP}\left(\mathrm{SiO}_{2}-\right)-\mathrm{RhB}-(-)^{d}$ & $1: 0$ & - & 1.0 & - \\
\hline $\mathrm{NP}\left(\mathrm{SiO}_{2}-\right)-(-): \mathrm{Fl}^{d}$ & $0: 0.5$ & 1.0 & - & - \\
\hline
\end{tabular}

${ }^{a}$ Silica nanoparticles $\left(\mathrm{SiO}_{2} \mathrm{NPs}\right)$ with the incorporation of fluorescein (Fl) and rhodamine $\mathrm{B}(\mathrm{RhB})$ fluorophores. ${ }^{b} \mathrm{Different}$ ratios of $[\mathrm{RhB}]$ and $[\mathrm{Fl}]$ concentrations incorporated within $\mathrm{NP}\left(\mathrm{SiO}_{2}-\right)-\mathrm{RhB}:$ Fl. The ratio $1: 1$ corresponds to $1.0 \mu \mathrm{M} .{ }^{c}$ Ratio of intensities of emission bands of $\mathrm{Fl}$ at $520.0 \mathrm{~nm}$ and $\mathrm{RhB}$ at $560.0 \mathrm{~nm} .{ }^{d} \mathrm{NP}\left(\mathrm{SiO}_{2}-\right) \mathrm{RhB}: \mathrm{Fl}$ corresponds to multi-coloured NPs, and $\mathrm{NP}_{\left(\mathrm{SiO}_{2}-\right)} \mathrm{RhB}$ and $\mathrm{NP}\left(\mathrm{SiO}_{2}-\right) \mathrm{Fl}$ correspond to mono-coloured NPs. The excitation wavelength applied was $480.0 \mathrm{~nm}$, which corresponds to the optimal excitation of Fl as a fluorescent energy donor reporter. 


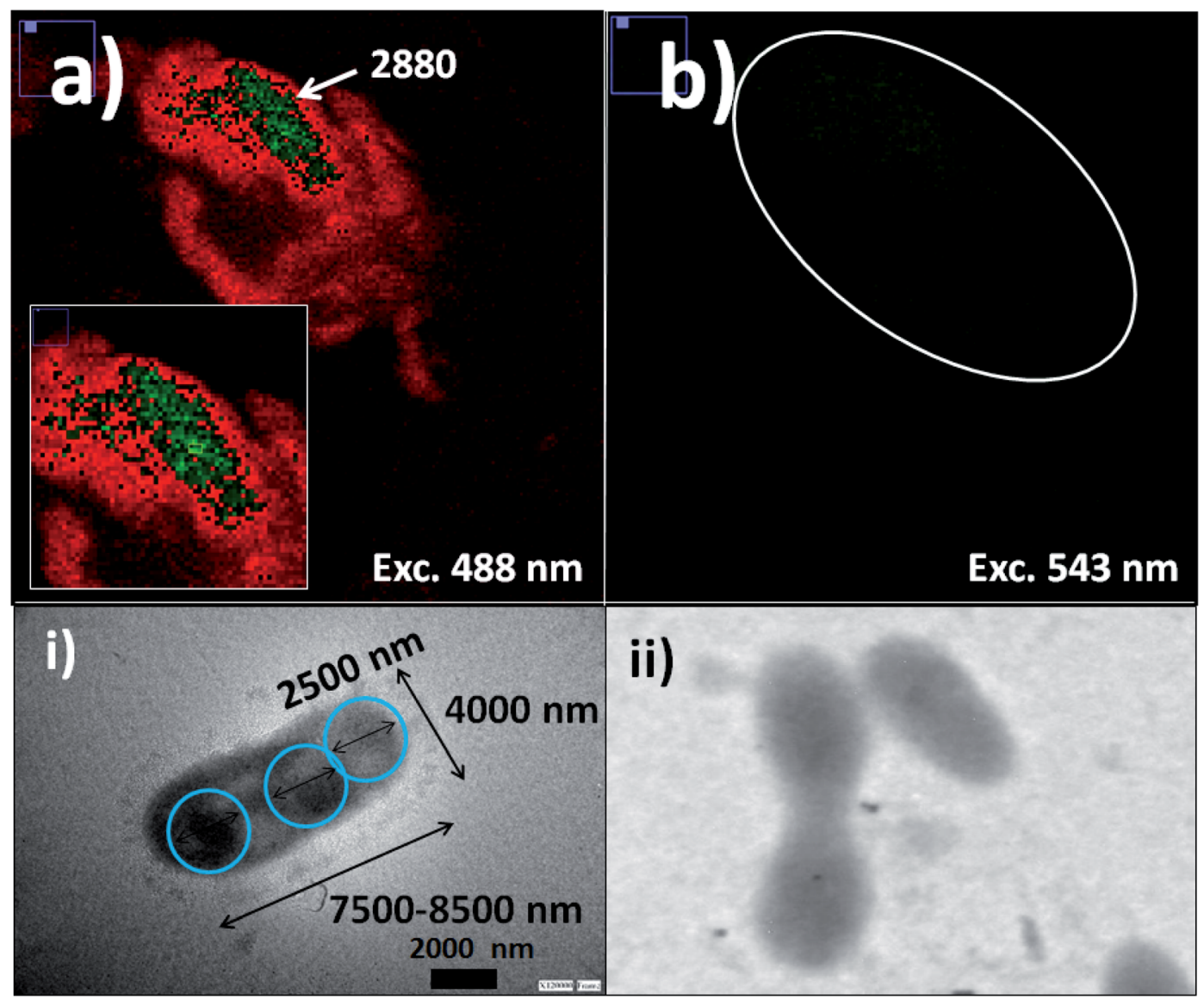

Fig. 8 Cyanobacteria labelling with fluorescent silica nanoparticles: (a) laser fluorescence microscopy imaging of labelled cyanobacteria with $\mathrm{SiO}_{2}-\mathrm{Fl}$ nanoparticles with excitation at $488.0 \mathrm{~nm}$; (b) laser fluorescence microscopy imaging of labelled cyanobacteria with $\mathrm{SiO}{ }_{2}-\mathrm{RhB}$ nanoparticles with excitation at $555.0 \mathrm{~nm}$. Inset images: (i) and (ii) TEM images of labelled cyanobacteria with $\mathrm{SiO}_{2}$ and non-labelled cyanobacteria, respectively. For the laser fluorescence microscopy image edition, a red-green and green color LUT was applied for optimal results depending on the emission intensities from the nano-biostructure.

produced due to the close intermolecular proximity accompanied by the formation of quenched dimeric species. ${ }^{40}$ This phenomenon was shown by other similar derivatives such rhodamine $6 \mathrm{G}$ adsorbed on titanium oxide nanoparticles depending on the added concentration. ${ }^{41}$

However, tuning concentrations to obtain the right ratio of $\mathrm{RhB}: \mathrm{Fl}$ was required to obtain FRET pairs. The RhB/Fl emission bands were controlled and maximized within confined silica nanoparticles avoiding the quenching contribution.

Then, with excitation at $515.0 \mathrm{~nm}$, for optimal excitation of $\mathrm{RhB}$ as fluorescent energy acceptor and partially $\mathrm{Fl}$ as fluorescent energy donor, noted were diminished emissions accompanied by small intensity increase with addition of higher $\mathrm{Fl}$ concentrations. Moreover for higher RhB concentrations a quenching effect was observed. In this manner it was shown how by controlling the excitation wavelength it was possible to activate or deactivate different fluorescent emission pathways within a confined volume at the nanoscale with incorporation of different emitters (Fig. 7).

In this manner these nanoparticles showed excellent properties for nano-tracking and biolabelling applications based on their tuneable emission properties. Moreover it should be highlighted that these silica nanoplatforms showed potential chemical surface modifications for bioconjugation by covalent and non-covalent interactions based on their polar surfaces given by hydroxyls of silanol groups. At this point, it should be mentioned for example that already reported were interactions of aminated and thiosulfonated modified silica nanoparticles with Escherichia coli, ${ }^{42}$ permitting homogeneous deposition of the nanoparticles over these biostructures. In this study was shown the implication of non-covalent interactions such as polar interactions, van der Waals forces, and strong hydrogen bonding between the biomolecules placed on the bacterial membrane and the modified hydroxyl groups and free silanols.

For these reasons their applications were evaluated as nanolabellers for cyanobacteria labelling.

\subsection{Bioimaging based on fluorescent cyanobacteria nano- labelling}

In order to apply these fluorescent silica nanoparticles for cyanobacteria labelling, variable aliquots of bacteria were added within concentrated conditions of the different optimized fluorescent nano-labellers. To do that were chosen smaller 


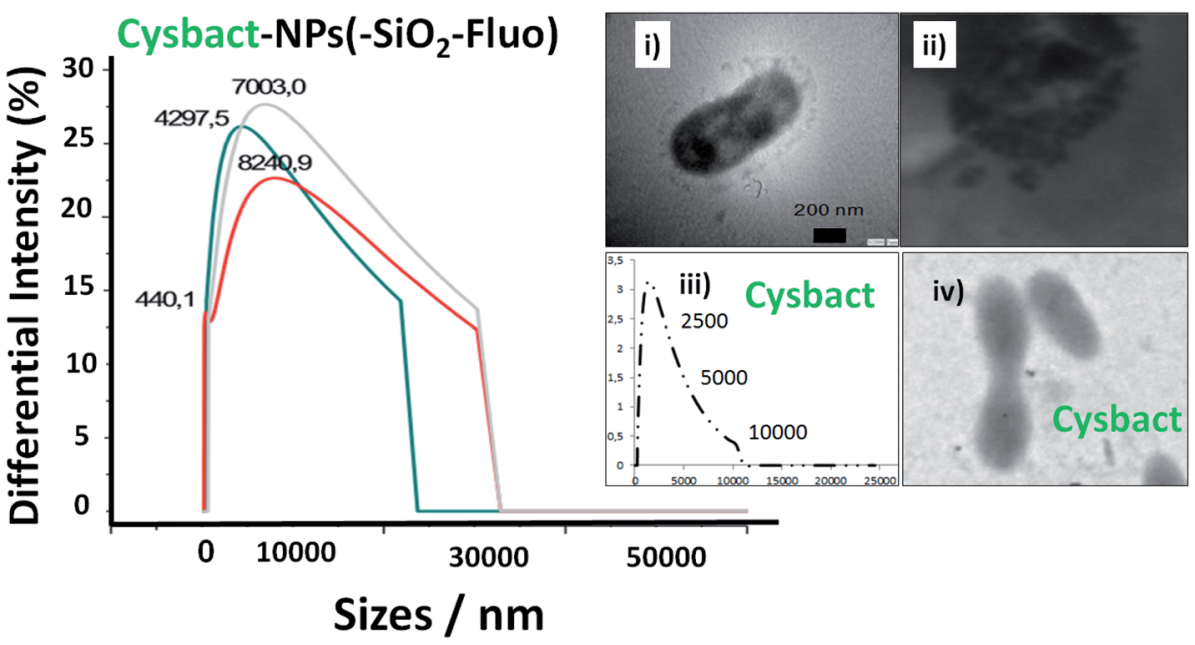

Fig. 9 Distribution of sizes by DLS of labelled cyanobacteria with fluorescent silica nanoparticles within a 10 minute interval of time. Blue, grey, and red lines corresponded to 1, 5, and 9 minutes, respectively. Inset images: (i) a TEM image of an individual labelled cyanobacterium; (ii) a TEM image of aggregated labelled cyanobacteria; (iii) the distribution of sizes of non-labelled cyanobacteria (cysbact) by DLS; and (iv) a TEM image of non-labelled cyanobacteria (cysbact).

nanoparticle sizes of $180-200 \mathrm{~nm}$ due to their improved resolution at the nanoscale accompanied by strong emission intensities and stronger non-covalent interactions between nanoparticles based on their van der Waals interactions predicted from Hamaker constants. ${ }^{43}$ In addition, exo-cellular polysaccharides produced from cyanobacteria ${ }^{44}$ generated, in the absence of nano-labellers, strong inter-cyanobacteria interactions. While in the presence of the modified silica nanoparticles additional strong hydrogen bridges could be involved in their interactions and targeted depositions over the biostructures. So, based on strong van der Waals, polar and noncovalent interactions, and hydrogen bridges between cyanobacteria and silica nano-labellers, their interactions were evaluated by different microscopy methodologies. In this manner smaller fluorescent nano-labeller sizes showed better bio- and nano-surface ratio. In this manner could be deposited a higher number of nanoparticles per biostructure. However, it should be mentioned that larger sizes interacted as well with the cyanobacterial biostructures.

Thus was observed by laser fluorescence microscopy the generation of bioimaging from small cyanobacterial aggregates formed from tetramers to higher nano-bio-aggregates. Cyanobacterial labelling with $\mathrm{NPs}-\left(\mathrm{SiO}_{2}-\mathrm{Fl}\right)$ showed enhanced emission from labelled bio-surfaces with optimal laser excitation at $488.0 \mathrm{~nm}$. LUT edition image with dual red-green color permitted obtaining the variations of the emission intensities from the nano-biostructures (Fig. 8a). The stronger green intensities corresponded to homogeneous NPs- $\left(\mathrm{SiO}_{2}-\mathrm{Fl}\right)$ nanolabeller depositions; while the multi-coloured silica nanoparticles produced quenched emissions as well as in the presence of labelled cyanobacteria with $\mathrm{NPs}-\left(\mathrm{SiO}_{2}-\mathrm{RhB}\right)$ (Fig. $\left.8 \mathrm{~b}\right)$ at both laser excitations applied. By optimal excitation of $\mathrm{RhB}$ at 543.0 and $555.0 \mathrm{~nm}$, homogeneous low emission was recorded from the labelled biosurfaces (Fig. 8b) as was observed for NPs$\left(\mathrm{SiO}_{2}-\mathrm{RhB}\right)$ biolabelling. But, from non-labelled cyanobacteria drastically diminished bioimaging was recorded due to their intrinsic low fluorescence emissions. ${ }^{45}$

The deposition of silica nanolabellers was corroborated by TEM (inset image (i) of Fig. 8) by increased contrast from labelled bacteria in comparison to non-labelled cyanobacteria (inset image (ii) of Fig. 8).

Moreover, DLS measurements showed higher distribution of labelled bacterial sizes than non-labelled cyanobacteria. Smaller average sizes within 5000.0-7500.0 nm range and larger aggregates as well were recorded by DLS (Fig. 9). The sizes were verified by TEM that corresponded to labelled single, dimeric and trimeric cyanobacteria (inset (i) of Fig. 9), and larger aggregates (inset (ii) of Fig. 9). The labelled biostructure sizes were larger than the non-labelled ones (inset (iii) of Fig. 9) measured by DLS. The labelled cyanobacteria showed higher contrasted images than non-labelled biostructures (inset (iv) of Fig. 9). This fact was explained by the presence of coloured silica nanoparticles with higher electron density from the highly conjugated chromophores incorporated within the silica nanoparticles.

In addition, it should be added that the sizes measured by DLS of the nano-biostructure aggregates with $\mathrm{NPs}-\left(\mathrm{SiO}_{2}-\mathrm{Fl}\right)$ corresponded to those observed by laser fluorescence microscopy (Fig. 10a). From these hot-spots only were generated stronger emissions. In optimized conditions, non-aggregated free nano-labellers were observed. While, in the absence of the cyanobacteria were observed single free $\mathrm{NPs}-\left(\mathrm{SiO}_{2}-\mathrm{Fl}\right)$ nanolabellers, and from dimeric to tetrameric species as well (Fig. 10b), but not observed in any case were similar shapes, aggregates and sizes as was observed for the nano-biostructures (Fig. 10b).

The free nanolabellers and small nanoaggregates observed were confirmed in colloidal dispersion in the absence of cyanobacteria by DLS measurements. Dimeric and trimeric species of NPs- $\left(\mathrm{SiO}_{2}-\mathrm{Fl}\right)$ nanoparticles were determined (Fig. 11a), as well as single nanoparticles (Fig. 11b). These colloidal 

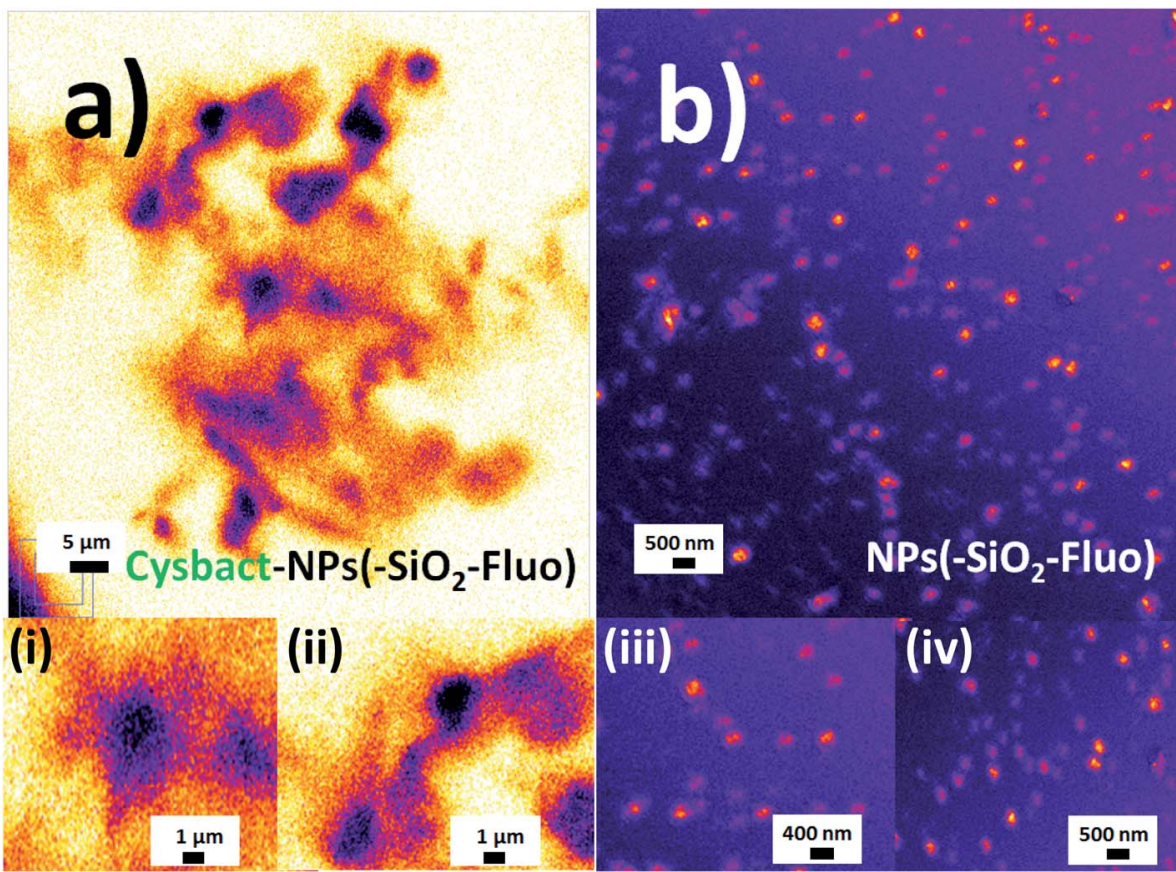

(ii)
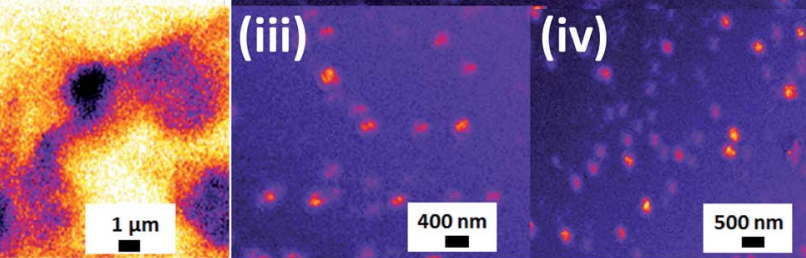

Fig. 10 Laser fluorescence microscopy: (a) aggregated labelled cyanobacteria with mono-coloured $\mathrm{SiO}_{2}-\mathrm{Fl}$ nanoparticles (cysbact-NPs($\mathrm{SiO}_{2}-$ Fluo); (b) a colloidal dispersion of mono-coloured $\mathrm{SiO}_{2}-\mathrm{Fl}$ nanoparticles. Inset images: (i) and (ii) zoomed images of dimeric and trimeric forms of labelled cyanobacteria, respectively; (iii) and (iv) zoomed images of mono-coloured $\mathrm{SiO}_{2}-\mathrm{Fl}$ nanoparticles. For the laser fluorescence microscopy image edition the fire LUT was applied.
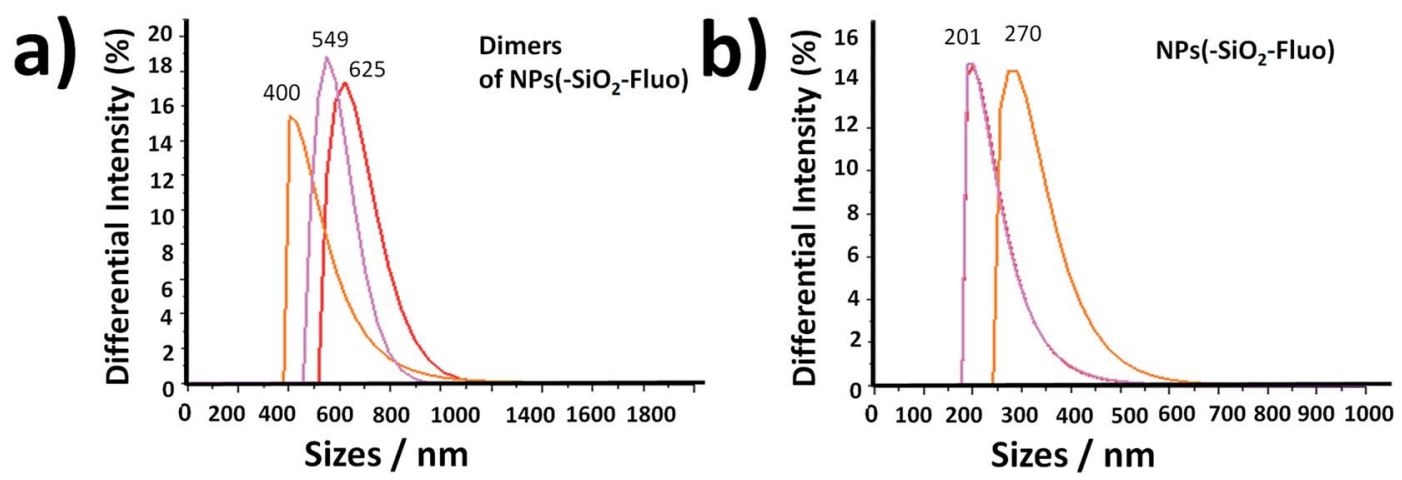

Fig. 11 The distribution of smaller sizes in a colloidal dispersion by DLS of (a) dimeric nanoarchitectures of fluorescent silica NPs; and (b) individual fluorescent silica NPs. Size distribution measurements were carried out within 10 minutes. The pink, orange, and red lines correspond to 1,5 , and 9 minutes, respectively.

dispersions were stable within 10 minutes. After this period of time, they showed diminished intensities from decantation in colloidal dispersion. Therefore, this effect diminished the detection of the dispersed nanoparticles in the colloidal dispersion. However, by simple manual shaking they were redispersed. So, the colloidal dispersions were well stable and dispersible.

In this manner was confirmed the use of the fluorescent silica nanoparticles as nano-labellers by non-covalent interactions for cyanobacterial bioimaging.

The strong non-covalent interactions were explained by hydrogen bonding that showed higher strengths than other non-covalent interactions ${ }^{\mathbf{4 6 , 4 7}}$ with a high dependence of the electronic donor-acceptor lengths from the functional groups or atoms involved. ${ }^{48}$ This could explain some observations made by us with different real water samples with variable composition and possible interferences. However further experiments should be done in order to study the effect of possible interferences from real matrixes, as well as the possible incorporation of the nanolabellers within the biostructure.

From the literature the fluorescence technique showed high sensitivity for biolabelling, with an example application being the use of mannose-fluorescent functionalized polymer for Escherichia coli labelling and detection. ${ }^{49}$ Moreover, modified silica nanoparticles being aminated and thiosulfonated were used for non-covalent depositions on Escherichia colit ${ }^{\mathbf{4 2}}$ as 
previously discussed. Moreover, it should be highlighted the recent development by us of ultraluminescent gold core-shell silica nanoparticles based on MEF for individual Escherichia coli detection. ${ }^{\mathbf{1 3 , 5 0}}$ In addition, cyanobacterial non-specific labelling with quantum dots ${ }^{51}$ on filamentous structures of cyanobacteria was reported as well. In this way, it should be mentioned that cyanobacteria could generate biofilm formation by their exocellular polysaccharide production and higher aggregates as well. $^{52}$ Thus, in the context of antifouling nanoparticle applications, non-covalent deposition of silanized magnetic nanoparticles has been reported ${ }^{53}$ and PEG-silver nanoparticles ${ }^{54}$ as well as other types of nanomaterials. ${ }^{55}$

So, to the best of our knowledge, the utilisation of silica nanoparticles for non-covalent luminescent biolabelling applications of cyanobacteria has not been reported yet; however non-covalent depositions of different nanoparticles and nanomaterials were already reported.

\subsection{Static and time-resolved fluorescence characterization by mono- and multi-coloured nano-silica cyanobacteria labelling}

Based on the biolabelling methodology described and due to variable emission properties observed for the different monocoloured and multi-coloured fluorescent silica nanoparticles, their static and time-resolved emissions were evaluated quantitatively.

First, it should be mentioned that variable absorption and low-intensity emission were reported for different types of cyanobacteria. ${ }^{56}$ In particular the wild population of Microcystis aeruginosa studied showed a higher absorption band in the UV region around $350.0 \mathrm{~nm}$. In concentrated conditions static fluorescence measurements showed 4 times higher emission intensities than cyanobacteria labelled with $\mathrm{NPs}_{-}-\mathrm{SiO}_{2}-\mathrm{Fl}$ nanolabellers and even higher than with NPs- $\left(\mathrm{SiO}_{2}\right)-\mathrm{RhB}$ and multicoloured NPs-( $\left.\mathrm{SiO}_{2}-\mathrm{RhB}-\mathrm{Fl}\right)$ nanoparticles (Fig. 12a). This fact was clearly explained by the optimal excitation of fluorescent photosystem and negligible absorption from the fluorescent reporters incorporated within the different silica nanoparticles. This fact showed the important role of the fluorophores and control of the light recorded from the non-labelled biostructure and labelled biostructure by the excitation wavelength applied. But, by the optimal excitation of $\mathrm{Fl}$ as a fluorescent energy donor reporter at $480.0 \mathrm{~nm}$, up to ten times higher emission intensities were recorded with the application of NPs- $\left(\mathrm{SiO}_{2}-\mathrm{Fl}\right)$ nanoparticles than non-labelled cyanobacteria. However, the attendant enhanced fluorescence emission from multi-coloured NPs- $\left(\mathrm{SiO}_{2}-\mathrm{RhB}-\mathrm{Fl}\right)$ nano-labellers observed from free nanoparticles was not observed. Instead were recorded diminished emissions with only $25 \%$ of the increase in comparison to nonlabelled cyanobacteria. While with $\mathrm{NPs}-\left(\mathrm{SiO}_{2}-\mathrm{RhB}\right)$ nanolabellers was observed $10 \%$ reduction in comparison to nonlabelled cyanobacteria (Fig. 12b). The main fact to explain this was the diminution of the nano-biostructures with $\mathrm{NPs}_{-} \mathrm{SiO}_{2}-$ ( $\mathrm{RhB}-\mathrm{Fl})$ nano-labellers in comparison to $\mathrm{NPs}-\left(\mathrm{SiO}_{2}-\mathrm{Fl}\right)$ in the absence of the fluorescent energy acceptor RhB.
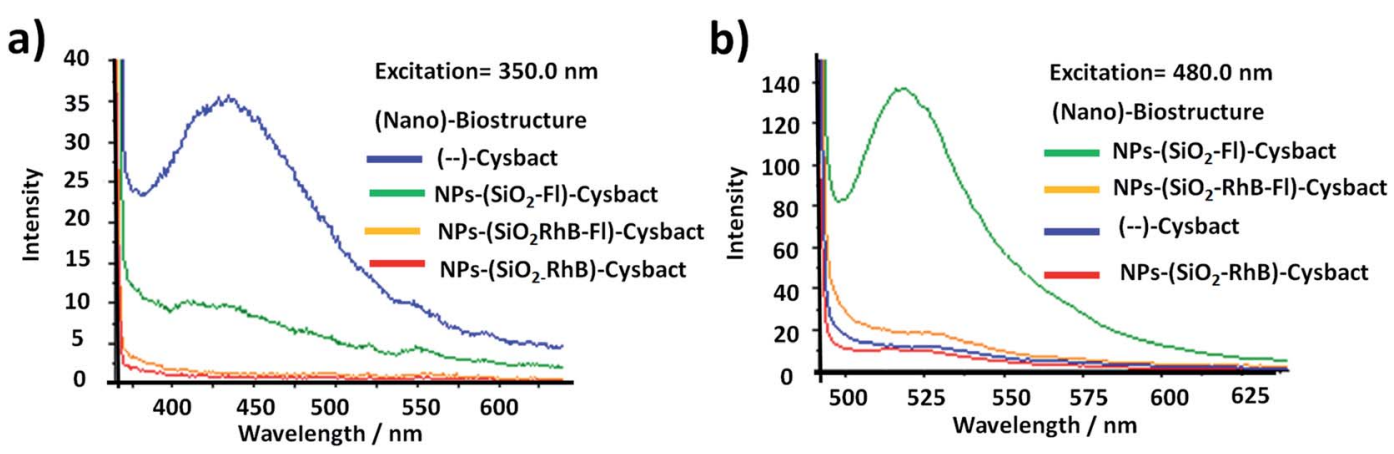

Fig. 12 Fluorescence emission of non-labelled and labelled cyanobacteria with fluorescent $\mathrm{SiO}_{2}$ nanoparticles (NPs-SiO $\left.-\mathrm{Fluo}\right)$ at (a) an excitation wavelength of $350.0 \mathrm{~nm}$, which corresponds to the maximal absorption wavelength of cyanobacteria; and (b) at an excitation wavelength of $480.0 \mathrm{~nm}$, which corresponds to the maximal absorption wavelength of fluorescein (Fl) as a fluorescent energy donor reporter.
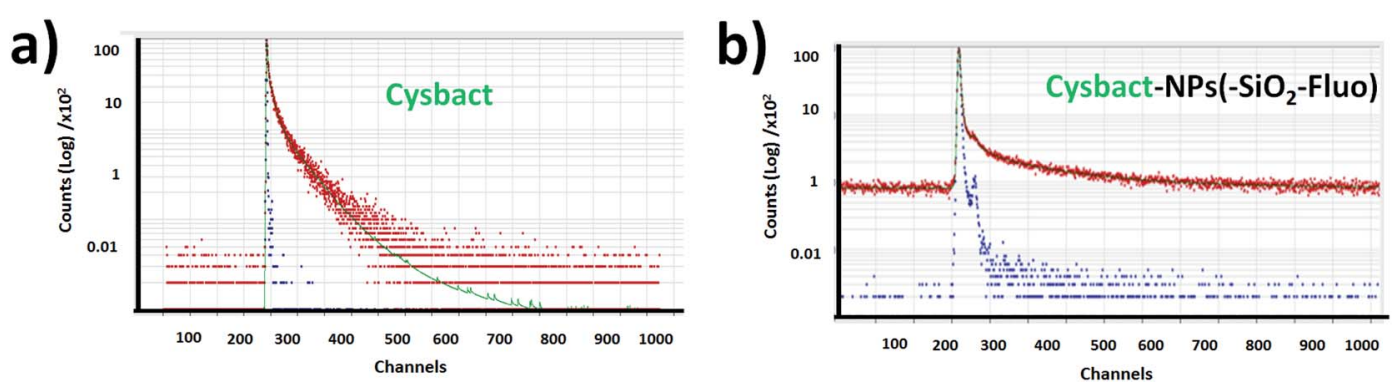

Fig. 13 Fluorescence lifetime decays within colloidal dispersions of (a) labelled cyanobacteria with mono-coloured silica nanoparticles by the incorporation of fluorescein (cysbact-NPs $\left(\mathrm{SiO}_{2}-\mathrm{Fl}\right)$ ) and (b) cyanobacteria (cysbact). 
Table 2 Fluorescence lifetime decay measurements of nano-biostructures obtained based on cyanobacteria labelled with mono-coloured $\mathrm{SiO}_{2}-\mathrm{Fl}$ and multi-coloured $\mathrm{SiO}_{2}-\mathrm{RhB}-\mathrm{Fl} \mathrm{NPS}$

\begin{tabular}{lcclc}
\hline Nano-biostructure $^{a}$ & $\tau_{1}(\mathrm{~ns})$ & $\tau_{2}(\mathrm{~ns})$ & $\tau_{3}(\mathrm{~ns})$ & $\tau_{4}(\mathrm{~ns})$ \\
\hline$(\mathrm{RhB}-\mathrm{Fl})^{b}$ & $0.04 \pm 0.02$ & $\mathbf{3 . 6 5} \pm 0.02$ & $(-)$ & $(-)$ \\
$(\mathrm{Fl})^{c}$ & $0.91 \pm 0.01$ & $3.97 \pm 0.02$ & $(-)$ & $\mathbf{0 . 3 0 0} \pm 0.001$ \\
$(\mathrm{RhB}-\mathrm{Fl})-$ cysbact $^{d}$ & $0.002 \pm 0.001$ & $0.008 \pm 0.002$ & $\mathbf{0 . 9 9 0} \pm 0.003$ & $\mathbf{5 . 9 0 0} \pm 0.002$ \\
$(\mathrm{Fl})-$ cysbact $^{e}$ & $0.02 \pm 0.01$ & $0.120 \pm 0.001$ & $30.620 \pm 0.002$ & $\mathbf{6 . 1 0 0} \pm 0.002$ \\
$\left(-\right.$ Cysbact $^{f}$ & $\mathbf{1 . 5 3 0} \pm 0.003$ & $\mathbf{6 . 1 2 0} \pm 0.002$ & $61.240 \pm 0.004$
\end{tabular}

${ }^{a}$ Cyanobacteria of Microcystis aeruginosa (cysbact) were evaluated for nano-biolabelling with fluorescent $\mathrm{SiO}_{2} \mathrm{NPs}^{b} \mathrm{Free} \mathrm{SiO}_{2}-\mathrm{RhB}^{\mathrm{F}} \mathrm{Fl} \mathrm{NPs}$ with Fl as the fluorescent energy donor and $\mathrm{RhB}$ as the resonant energy acceptor with a maximal absorption wavelength of $470.0 \mathrm{~nm}$ in the absence of cyanobacteria. ${ }^{c}$ Free $\mathrm{SiO}_{2}-\mathrm{Fl} \mathrm{NPs}$ with $\mathrm{Fl}$ as the fluorescent reporter with a maximal absorption wavelength at $480.0 \mathrm{~nm}$. ${ }^{d}$ Labelled cyanobacteria with $\mathrm{NPs}-\left(\mathrm{SiO}_{2}-\mathrm{RhB}-\mathrm{Fl}\right)$ ((RhB-Fl)-cysbact). ${ }^{e}$ Labelled cyanobacteria with $\mathrm{NPs}^{-}\left(\mathrm{SiO}_{2}-\mathrm{Fl}\right) \quad((\mathrm{Fl})-\mathrm{cysbact}) .{ }^{f} \mathrm{Non}-\mathrm{labelled}$ cyanobacteria $((-)$-cysbact).

In order to complete this study for a well understanding of the emission pathways, fluorescence lifetime decays were measured of the free nano-labellers and labelled cyanobacteria.

For multi-coloured and mono-coloured nanoparticles were recorded bi-exponential fluorescent lifetime decays ( $\tau_{1}$ and $\left.\tau_{2}\right)$. For mono-coloured silica nanoparticles were recorded a shorter component related to scattering $\left(\tau_{1}\right)$ and longer decay $\left(\tau_{2}\right)$ related to the confined fluorophores within the silica nanoarchitecture (Table 1). These values correlated with reported literature for free $\mathrm{Fl}^{35}$ and $\mathrm{RhB}^{36}$ fluorophores slightly modified by scattering. While for multi-coloured silica nanoparticles with optimal excitation of $\mathrm{Fl}$ as fluorescent energy donor reporter, a $\tau_{2}$ shortening of $15 \%$ was obtained. This fluorescence lifetime decay shortening was accompanied by $25 \%$ and $35-40 \%$ emission intensity increases recorded by static fluorescence and laser fluorescence microscopy respectively. This enhancement in the presence of both emitters accompanied by diminished fluorescence lifetime decays supported the improved emission pathway based on FRET already observed and discussed in connection with laser fluorescence microscopy.

Then from labelled cyanobacteria were recorded multiexponential decays related to the emission from the different components of the nano-biostructures formed by various chromophores and emitters from the nano-labellers and photosynthetic systems of cyanobacteria. For non-labelled cyanobacteria was recorded tetra-exponential decay fitting (Fig. 13a); $\tau_{1}$ and $\tau_{2}$ of 1.53 and 6.120 ns correlated with shorter and longer fluorescent lifetime decays, while $\tau_{3}$ and $\tau_{4}$ of 30.62 and $61.24 \mathrm{~ns}$ were related to modified emission from more aggregated bacteria (Table 2). As was already reported for these types of cyanobacteria, variable fluorescent lifetime decays were collected depending on their chromophore compositions. ${ }^{57}$ However faster decays related to 0.75 to $3.0 \mathrm{~ns}$ interval values were reported for different molecular composition of photosynthetic systems, as well as, depending on their state of aggregation, longer components being recorded..$^{58}$ So, the tetraexponential fitting showed clearly reduced fluorescence lifetime decays (Fig. 13b) in comparison to non-labelled cyanobacteria (Fig. 13a). Thus, for cyanobacteria labelled with NPs-( $\left.\mathrm{SiO}_{2}-\mathrm{Fl}\right)$ nanoparticles $\left(\mathrm{SiO}_{2}-\mathrm{Fl}\right.$-cysbact $)$ were recorded diminished shorter and longer fluorescent lifetime decays. Values of $\tau_{1}, \tau_{2}$, and $\tau_{3}$ of $0.02,0.120$, and 0.99 ns respectively were determined, and $\tau_{4}$ of $6.10 \mathrm{~ns}$ (Table 2). Noted are the reduced values of $\tau_{2}$ and $\tau_{3}$ for NPs- $\left(\mathrm{SiO}_{2}-\mathrm{Fl}\right)$-cysbact in comparison to $\tau_{1}$ and $\tau_{2}$ for non-labelled cyanobacteria. In addition it should be mentioned that these reductions of lifetime decays were accompanied by $35-40 \%$ higher emission intensities from nano-biosurfaces than from free NPs- $\left(\mathrm{SiO}_{2}-\mathrm{Fl}\right)$ nano-labellers, with up to 10 times higher emissions than non-labelled cyanobacteria. However, from labelled multi-coloured cyanobacteria with NPs$\left(\mathrm{SiO}_{2}-\mathrm{RhB}-\mathrm{Fl}\right)$ nano-labellers, drastic reduction of emission intensities was recorded accompanied by fluorescence lifetime decay shortening. The values of $\tau_{1}, \tau_{2}$, and $\tau_{3}$ were even lower than with NPs- $\left(\mathrm{SiO}_{2}-\mathrm{Fl}\right)$ nano-labelling (Table 2); however the transferred energy was conducted within a radiative pathway with a lower quantum yield that generated the reduction in intensity.

This fact was correlated with fluorescence emission bands recorded from time-gated fluorescence in intact blue-green and red algae from B-phycoerythrin as intermediate chromophore in their complex photosynthetic systems that showed two emission bands centered at 530.0 and $645.0 \mathrm{~nm}$ selectively excited at $540.0 \mathrm{~nm} .{ }^{59}$ From this it was observed that up to 4 times higher emissions could be obtained from the emission band centered at $530.0 \mathrm{~nm}$ than at $645.0 \mathrm{~nm}$. The mentioned differences showed the relative quantum yields between the chromophores involved in the emissions from non-labelled cyanobacteria that in the presence of the mono-coloured and multi-coloured nano-labellers coupled different bacterial chromophores via a bio-FRET pathway. In the presence of monocoloured NPs- $\left(\mathrm{SiO}_{2}-\mathrm{Fl}\right)$ nano-labellers clear enhancements were found explained by the coupling based on the welloverlapping shorter emission band with the cyanobacterial chromophore with higher quantum yield centered at $530.0 \mathrm{~nm}$. While in the presence of the mono-coloured NPs- $\left(\mathrm{SiO}_{2}-\mathrm{RhB}\right)$ and multi-coloured $\mathrm{NPs}-\left(\mathrm{SiO}_{2}-\mathrm{RhB}-\mathrm{Fl}\right)$ nano-labellers, the diminished emission was due to the coupling with the lower quantum yield chromophore with the longer wavelength band centered at $645.0 \mathrm{~nm}$. In this manner in the presence of labelled cyanobacteria with $\mathrm{RhB}$ emitter was recorded a diminished emission pathway conducted via bio-FRET, which in the presence of RhB-Fl pair was slightly enhanced but it was not 
proportional to the enhancements recorded for free $\mathrm{NPs}_{-}\left(\mathrm{SiO}_{2}-\right.$ RhB-Fl) nano-labeller.

To the best of our knowledge, there has been no previous report of an enhanced bio-structure like this one by controlling targeted emissions through different quantum yielding natural photo-receptors. However, this is a high-impact research field within biophotonics such as already recently reported for living lasers $^{60}$ based on the incorporation of green fluorescent proteins in cells. Thus the importance was shown of the design of nano-engineered materials as optical gain media ${ }^{61}$ for bioapplications. In a similar manner, it could be mentioned the synthesis and fabrication of new materials for the design of miniaturized devices and instrumentation for targeted light
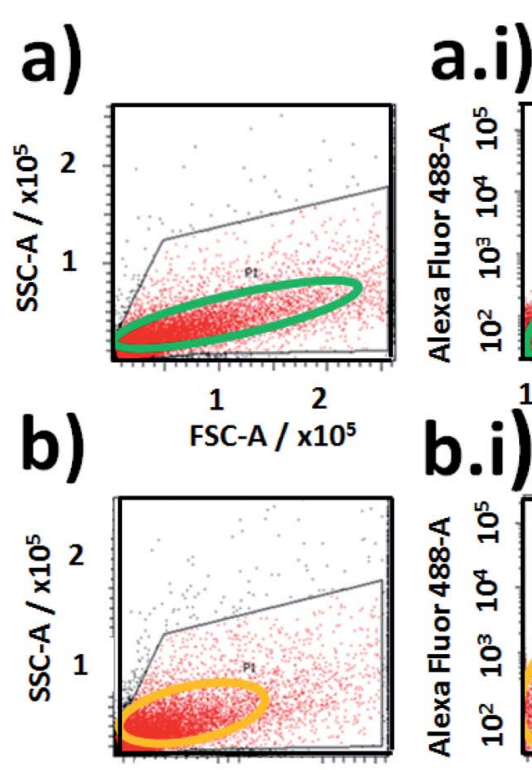

12
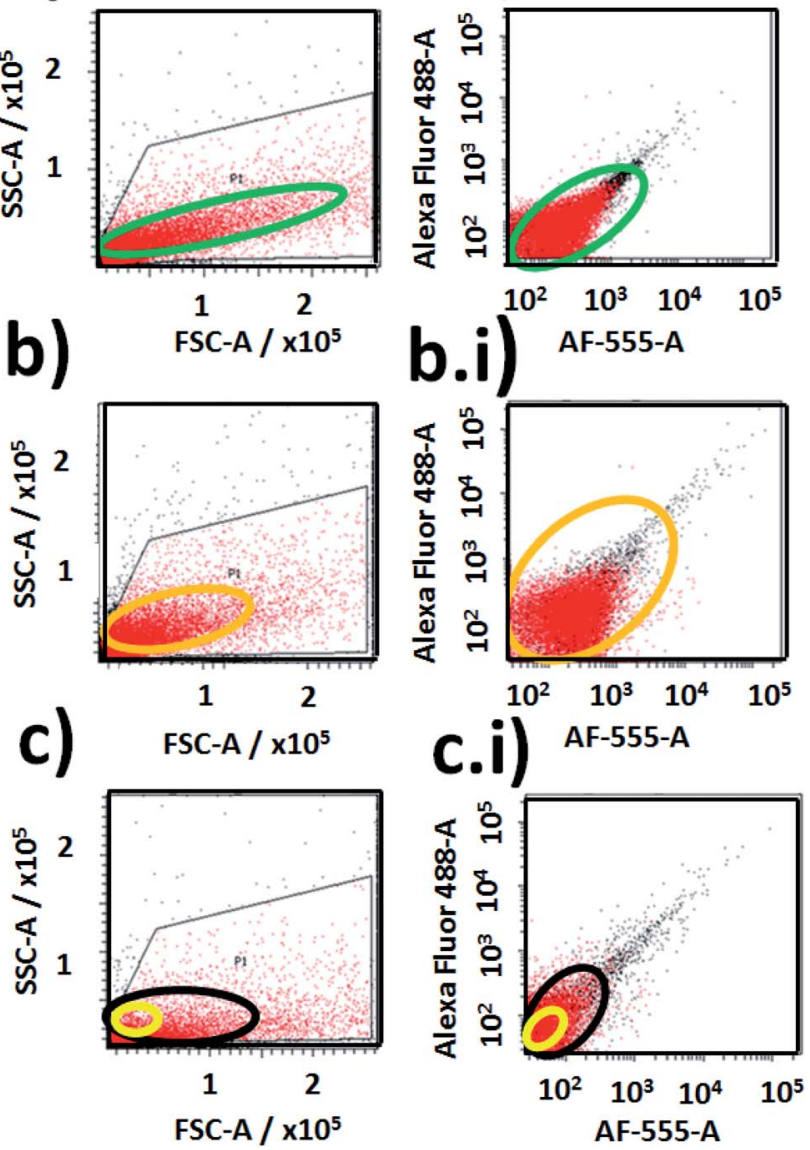

AF-555-A

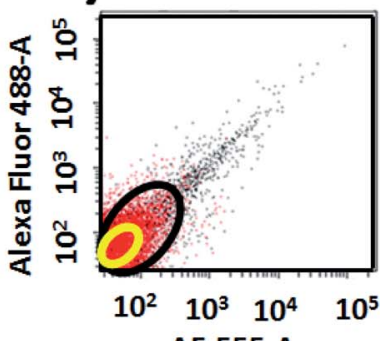

Fig. 14 Fluorescence event detection via in-flow cytometry of labelled and non-labelled cyanobacteria: (a) and (a.i) correlation plots of SSC-A vs. FSC-A and a graph of fluorescent event counting between Alexa-Fluor 488-A vs. Alexa-F555-A from labelled cyanobacteria with multi-coloured NPs- $\left(\mathrm{SiO}_{2}-\mathrm{RhB}-\mathrm{Fl}\right)$ nanoparticles; (b) and (b.i) correlation plots of SSC-A vs. FSC-A and a graph of fluorescent event counting between Alexa-Fluor 488-A vs. Alexa-F555-A from labelled cyanobacteria with mono-coloured $\mathrm{NPs}-\left(\mathrm{SiO}_{2}-\mathrm{Fl}\right)$ nanoparticles; (c) and (c.i) correlation plots of SSC-A vs. FSC-A and a graph of fluorescent event counting between Alexa-Fluor 488-A vs. Alexa-F555-A from non-labelled cyanobacteria. Note: free mono-coloured NPs$\left(\mathrm{SiO}_{2}-\mathrm{Fl}\right)$ and multi-coloured $\mathrm{NPs}-\left(\mathrm{SiO}_{2}-\mathrm{RhB}-\mathrm{Fl}\right)$ nanolabellers were detected in a reduced sized area highlighted with a yellow oval within the highlighted black oval in (c) for non-labelled cyanobacteria. delivery ${ }^{62}$ for sensing and bioimaging ${ }^{63}$ within confined biostructures and tissues.

In summary, the reported luminescent nanoplatforms showed variable and controlled emissions depending on the fluorescent emitter reporters incorporated within the silica nanoparticles. In the presence of the RhB-Fl FRET pairs, enhanced emissions were observed in comparison to monocoloured nanoparticles. However these enhancements were coupled via a bio-FRET pathway with 4-5 times lower cyanobacteria chromophore quantum yield that produced clear diminished emission from multi-coloured and mono-coloured silica nanoparticles in the presence of $\mathrm{RhB}$ as fluorescence energy acceptor and emitter (Scheme 2(i) and (ii)). And with mono-coloured NPs- $\left(\mathrm{SiO}_{2}-\mathrm{Fl}\right)$ nano-labelling was coupled the higher bacterial chromophore quantum yield that produced enhanced bio-FRET emissions (Scheme 2(iii)).

\subsection{Cyanobacteria detection by in-flow cytometry and laser fluorescence microscopy}

Then was evaluated the application of the developed nanobiolabelling methodology by in-flow cytometry with laser excitation and fluorescence detection. In order to do that, variable distributions were recorded of SSC and FSC (SSC: Side Scattered Light; and FSC: Foward Scattered Light) from the different labelled cyanobacteria and non-labelled biostructures (Fig. 14). As is known, it should be mentioned that the SSC parameter is a measurement of mostly refracted and reflected light that occurs at any interface within a cell where there is a change in refractive index. ${ }^{64}$ The SSC is collected at approximately 90 degrees to the laser beam by a collection lens and then redirected by a beam splitter to the appropriate detector. In this manner, the SSC parameter is proportional to cell granularity or internal complexity and it registers cleaner fluorescent event detections from samples with diminished background signalling. Moreover, the FSC is a measurement of mostly diffracted light and it is detected just off the axis of the incident laser beam in the forward direction by a photodiode. FSC provides a suitable method of detecting particles greater than a given size independent of their fluorescence and is therefore often used in immune-phenotyping to trigger signal processing. ${ }^{65}$

In addition variable fluorescent event detection counts were collected from the different samples with standard fluorescence parameters of Alexa-Fluor-488-A (laser excitation at $488.0 \mathrm{~nm}$ with emission filter placed at 530/30 nm) and AF-555-A (laser excitation at $555.0 \mathrm{~nm}$ with emission filter at $585 / 42 \mathrm{~nm}$ ) (Fig. 14).

For cyanobacteria labelled with $\mathrm{NPs}-\left(\mathrm{SiO}_{2}-\mathrm{RhB}-\mathrm{Fl}\right)$ and $\mathrm{NPs}-\left(\mathrm{SiO}_{2}-\mathrm{Fl}\right)$ nanoparticles, different distributions of SSC values were recorded. For cyanobacteria labelled with NPs$\left(\mathrm{SiO}_{2}-\mathrm{RhB} @ \mathrm{Fl}\right), \mathrm{SSC}$ values were recorded up to $\times 10^{5}$ (Fig. 14a); while for those labelled with $\mathrm{NPs}-\left(\mathrm{SiO}_{2}-\mathrm{Fl}\right)$, values of $1 \times 10^{5}$ and higher were collected (Fig. 14b). In this manner was recorded a higher number of fluorescent event detection counts of cyanobacteria labelled with $\mathrm{NPs}-\left(\mathrm{SiO}_{2}-\mathrm{Fl}\right)$ (Fig. $\left.14 \mathrm{~b}(\mathrm{i})\right)$ than with NPs-( $\left.\mathrm{SiO}_{2}-\mathrm{RhB}-\mathrm{Fl}\right)$ (Fig. 14a(i)). This fact was explained in terms of the enhanced bio-FRET pathway by the emission of the 

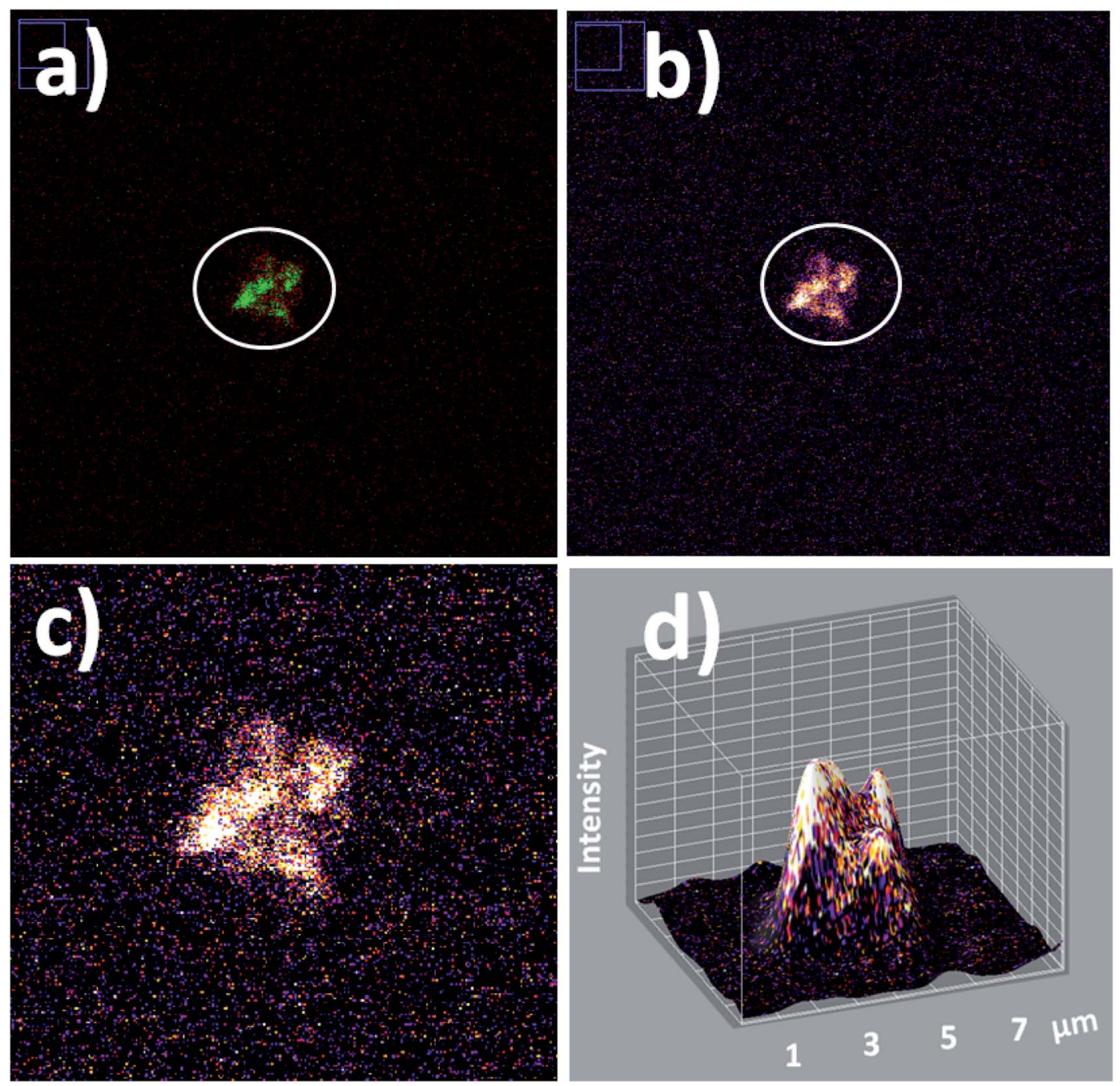

Fig. 15 Laser fluorescence microscopy of individual small cyanobacteria aggregates: (a) red-green LUT; (b) fire LUT applied; (c) zoomed fire LUT image; and (d) 3D fluorescent surfaces of bacterial tetramers. Laser excitation at $488.0 \mathrm{~nm}$.

$\mathrm{NPs}-\left(\mathrm{SiO}_{2}-\mathrm{Fl}\right)$ towards the higher quantum yielding photoreceptor of cyanobacteria previously discussed.

In addition, from the analysis of FSC was observed a higher number of detection values within a larger interval of FSC values for cyanobacteria labelled with $\mathrm{NPs}-\left(\mathrm{SiO}_{2}-\mathrm{RhB}-\mathrm{Fl}\right)$ (Fig. 14a), and lower FSC values within a shorter range of values for those labelled with $\mathrm{NPs}-\left(\mathrm{SiO}_{2}-\mathrm{Fl}\right)$ (Fig. 14b). This fact was supported by the larger sizes of the deposited NPs- $\left(\mathrm{SiO}_{2}-\mathrm{RhB}-\mathrm{Fl}\right)$ than NPs- $\left(\mathrm{SiO}_{2}-\mathrm{Fl}\right)$ nano-labellers.

For non-labelled cyanobacteria, the fluorescent event detection distributions as well as the detection event counting were different in comparison to the previously discussed labelled biostructures. Smaller detection surfaces were obtained from SSC $v s$. FSC plots (Fig. 14c), accompanied by a lower number of detection counts (Fig. 14c(i)) than for cyanobacteria labelled with NPs- $\left(\mathrm{SiO}_{2}-\mathrm{RhB}-\mathrm{Fl}\right)$ (Fig. $\left.14 \mathrm{a}, \mathrm{a}(\mathrm{i})\right)$ and $\mathrm{NPs}-\left(\mathrm{SiO}_{2}-\mathrm{Fl}\right)$ (Fig. 14b, b(i)). Moreover, it should be highlighted that the free mono-coloured NPs- $\left(\mathrm{SiO}_{2}-\mathrm{Fl}\right)$ and multi-coloured $\mathrm{NPs}_{-}\left(\mathrm{SiO}_{2}-\right.$ $\mathrm{RhB}-\mathrm{Fl})$ nano-labellers were detected in reduced sized areas within the distribution of non-labelled cyanobacteria (highlighted yellow oval in Fig. 14c).

In this manner it was possible to apply the nano-biolabellers for cyanobacteria detection and counting with a versatile in-flow technique such as cytometry. However, further experiments should be done to validate this methodology.

In addition in order to evaluate applications by detection of these biostructures at low concentrations based on fluorescent bioimaging, colloidal dispersions were prepared with lower cyanobacteria concentrations. In this manner, by application of optimal NPs- $\left(\mathrm{SiO}_{2}-\mathrm{Fl}\right)$ nano-labellers, smaller bacterial aggregates were recorded (Fig. 15a and b) formed by dimers to tetramers of cyanobacteria (Fig. 15c). From these nanobiosurfaces, strong luminescent intensities were generated that permitted faster detection and counting with 3D fluorescence plots (Fig. 15d).

Finally it should be highlighted that using the developed methodology, individual ultraluminescent nano-biostructures were collected by in-flow cytometry as well as their detections 
by laser fluorescence microscopy. And at this point it should be mentioned that the non-classical light collected was from confined intermolecular interactions within silica nanoplatforms that permitted targeted light delivery via bio-FRET on biostructures that generated varied controlled emissions depending on the emitters incorporated within the nanostructures. In this way, these results showed potential applications of this methodology within confined microfluidics chips ${ }^{66}$ for biodetection and biophotonics applications. ${ }^{67}$

\section{Conclusions}

Variable silica nano-emitters were developed, formed via different fluorescent emitters with different quantum yields in order to tune their emission intensities based on FRET. From mono-coloured silica nanoparticles with the incorporation of $\mathrm{Fl}$ or RhB fluorescent dyes, strongly emitting $220.0 \mathrm{~nm}$ luminescent nanoparticles were recorded, with proportional quantum yields; while from multi-coloured silica nanoparticles, enhanced emissions were collected from $240.0 \mathrm{~nm}$ nanoparticles based on FRET. Increases were seen until $40 \%$ for multi-coloured silica nanoparticles.

These nanoparticles were evaluated for cyanobacteria labelling by non-covalent interactions and detected by laser fluorescence microscopy and in-flow cytometry. Thus, by TEM and laser fluorescence microscopy, the interactions were observed between the polar silica surfaces and polysaccharides naturally produced by the cyanobacteria that permitted targeted nanoparticle depositions.

By laser fluorescence microscopy, variable intensities from the luminescent nano-biostructures were recorded depending on the nano-labeller applied. Highly luminescent multicoloured NPs- $\left(\mathrm{SiO}_{2}-\mathrm{RhB}-\mathrm{Fl}\right)$ generated diminished emissions in comparison to NPs- $\left(\mathrm{SiO}_{2}-\mathrm{Fl}\right)$. This fact was explained by a bio-FRET coupling pathway with low quantum yields of natural chromophores from the biostructure. While, the application of NPs- $\left(\mathrm{SiO}_{2}-\mathrm{Fl}\right)$ nano-labellers produced higher emission by bio-FRET coupling with natural chromophores with higher quantum yields (known as photosystem I and II respectively).

Optimal biolabelling conditions were applied for in-flow cytometry experiments for cyanobacteria detection and counting. From cyanobacteria labelled with $\mathrm{NPs}-\left(\mathrm{SiO}_{2}-\mathrm{Fl}\right)$ greater fluorescent event counts were recorded than with multicoloured NPs-( $\left.\mathrm{SiO}_{2}-\mathrm{RhB}-\mathrm{Fl}\right)$ and NPs-( $\left.\mathrm{SiO}_{2}-\mathrm{RhB}\right)$ nanolabellers. These results correlated with the results obtained via static fluorescence and laser fluorescence microscopy.

In this manner light delivery was achieved and controlled from confined fluorophores within silica nanoplatforms for biolabelling applications with optically active biomaterials. Finally, it should be mentioned that the enhanced emissions were recorded by a targeted bio-FRET pathway considering the intrinsic and natural chromophore compositions of the biostructures assayed. Thus, future applications to other types of biostructures were opened up based on light delivery from confined emitters.

\section{Conflicts of interest}

There are no conflicts to declare.

\section{Acknowledgements}

We would like to acknowledge the different grants and funds which have allowed us to accomplish this work. In particular, thanks to SECyT (Secretary of Science and Technology from the National University of Cordoba, UNC, Argentina) for the completion payment of the first Grant for Young Researchers that permitted the finishing of this research work. The authors gratefully acknowledge Professor M. Valeria Ame from the Research Center in Clinical Biochemistry and Immunology (Centro de Investigaciones en Bioquímica Clínica e Inmunología, CIBICI), Department of Clinical Biochemistry, Faculty of Chemical Sciences, National University of Cordoba, Argentina (Universidad Nacional de Cordoba, Argentina, UNC) for the research collaboration in progress. Moreover, thanks are extended to Professor Denis Boudreau from the Département de Chimie and Centre d'Optique, Photonique et Laser (COPL), Québec, Canada for the long-standing collaboration as well.

\section{Notes and references}

1 A. G. White, B. D. Gray, K. Y. Pak and B. D. Smith, Deep-red fluorescent imaging probe for bacteria, Bioorg. Med. Chem. Lett., 2012, 22, 2833-2836.

2 I. L. Medintz, A. R. Clapp, H. Mattoussi, E. R. Goldman, B. Fischer and J. M. Mauro, Self-assembled nanoscale biosensors based on quantum dot FRET donors, Nat. Mater., 2003, 2, 630-638.

3 K. S. Ahn, K. R. Lim, D. Jeong, B. Young Lee, K. S. Kim and W. Y. Lee, Fluorescence energy transfer inhibition bioassay for cholera toxin based on galactose stabilized gold nanoparticles and amine terminated quantum dots, Microchem. J., 2016, 124, 9-14.

4 M. Rioux, D. Gontero, A. V. Veglia, A. Guillermo Bracamonte and D. Boudreau, Synthesis of ultraluminiscent gold coreshell nanoparticles as nanoimaging platforms for biosensing applications based on metal enhanced fluorescence, $R S C A d v$., 2017, 7, 10252-10258.

5 K. Golberg, A. Elbaz, R. McNeil, A. Kushmaro, C. D. Geddes and R. S. Marks, Increased bioassay sensitivity of bioactive molecule discovery using metal-enhanced bioluminescence, J. Nanopart. Res., 2014, 16, 2770.

6 D. Palecek, P. Edlund, S. Westenhoff and D. Zigmatas, Quantum coherence as a witness of vibronically hot energy transfer in bacterial reaction center, Sci. Adv., 2017, 3, e1603141.

7 N. Samkharadze, G. Zheng, N. Kalhor, D. Brousse, A. Sammak, U. C. Mendes, A. Blais, G. Scappucci and L. M. K. Vandersypen, Strong spin-photon coupling in silicon, Science, 2018, 359(6380), 1123-1127.

8 B. Pernis, Silica and the immune system, Acta Biomed., 2005, 76(2), 38-44. 
9 P. Wang, L. Zhang, W. Zheng, L. Cong, Z. Guo, Y. Xie, L. Wang, R. Tang, Q. Feng, Y. Hamada, K. Gonda, Z. Hu, $\mathrm{X}$. Wu and X. Jiang, Thermo-triggered release of CRISPRCas9 system by lipid-encapsulated gold nanoparticles for tumor therapy, Angew. Chem., Int. Ed., 2018, 57, 1491-1496.

$10 \mathrm{H}$. Yoo and J. Pak, Synthesis of highly fluorescent silica nanoparticles in a reverse microemulsion through doublelayered doping of organic fluorophores, J. Nanopart. Res., 2013, 15, 160.

11 K. Zhang, Y.-J. Gao, P.-P. Yang, G.-B. Qi, J.-P. Zhang, L. Wang and $H$. Wang, Self-assembled fluorescent organic nanomaterials for biomedical imaging, Adv. Healthcare Mater., 2018, 1800344.

12 Q. Zeng, Y. Zhang, X. Liu, L. Tu, X. Kong and H. Zhang, Multiple homogeneous immunoassays based on a quantum dots-gold nanorods FRET nanoplatform, Chem. Commun., 2012, 48, 1781-1783.

13 M. Rioux, D. Gontero, A. V. Veglia, A. G. Bracamonte and D. Boudreau, Synthesis of ultraluminiscent gold core-shell nanoparticles as nanoimaging platforms for biosensing applications based on metal enhanced fluorescence, $R S C$ Adv., 2017, 7, 10252-10258.

14 A. Grégoire and D. BoudreauMetal-enhanced fluorescence in plasmonic waveguides, Nano-Optics: Principles Enabling Basic Research and Applications, NATO Science for Peace and Security Series B: Physics and Biophysics, et al., ed. B. Di Bartolo, Springer Science+Business Media Dordrecht, 2017, ch. 28, DOI: 10.1007/978-94-024-0850-8_28.

15 J. L. Vivero-Escoto, I. I. Slowing, B. G. Trewyn and V. S. Y. Lin, Mesoporous silica nanoparticles for intracellular controlled drug delivery, Small, 2010, 6(18), 1952-1967.

$16 \mathrm{~S}$. Li, Y. Liu, R. Xing and X. Yan, Covalently assembled dipeptide nanoparticles with adjustable fluorescence emission for multicolor bioimaging, ChemBioChem, 2018, 19, 1-7.

17 J. M. O'Neil, T. W. Davis, M. A. Burford and C. J. Gobler, The rise of harmful cyanobacteria blooms: the potential roles of eutrophication and climate change, Harmful Algae, 2012, 14, 313-334.

18 J. Chouler and M. Di Lorenzo, Water quality monitoring in developing countries; can microbial fuel cells be the answer?, Biosensors, 2015, 5, 450-470.

19 C. Jin, M. M. F. Mesquita, J. L. Deglint, M. B. Emelko and A. Wong, Quantification of cyanobacterial cells via a novel imaging-driven technique with an integrated fluorescence signature, Sci. Rep., 2018, 8, 9055.

20 T. S. Moore, C. B. Mouw, J. M. Sullivan, M. S. Twardowski, A. M. Burtner, A. B. Ciochetto, M. N. McFarland, A. R. Nayak, D. Paladino, N. D. Stockley, T. H. Johengen, A. W. Yu, S. Ruberg and A. Weidemann, Bio-optical properties of cyanobacteria blooms in Western Lake Erie, Frontiers in Marine Science, 2017, 4, 300.

21 N. Schuergers, T. Lenn, R. Kampmann, M. V. Meissner, T. Esteves, M. Temerinac-Ott, J. G. Korvink, A. R. Lowe, C. W. Mullineaux and A. Wilde, Cyanobacteria use microoptics to sense light direction, eLife, 2016, 5, e12620.
22 C. Graf, D. L. J. Vossen, A. Imhof and A. van Blaaderen, A general method to coat colloidal particles with silica, Langmuir, 2003, 19, 6693-6700.

23 N. Phonthammachai, J. C. Y. Kah, G. Jun, C. J. R. Sheppard, M. C. Olivo, S. G. Mhaisalkar and T. J. White, Synthesis of contiguous silica-gold core-shell structures: critical parameters and processes, Langmuir, 2008, 24(9), 5109-5112.

24 D. Brouard, M. Lessard Viger, A. G. Bracamonte and D. Boudreau, Label-free biosensing based on multilayer fluorescent nanocomposites and a cationic polymeric transducer, ACS Nano, 2011, 5, 1888-1896.

25 P. Pinchuk and K. Jiang, Size-dependent Hamaker constants for silver and gold nanoparticles, Proc. SPIE 9549, Physical Chemistry of Interfaces and Nanomaterials XIV, 95491J, 2015, pp. 1-4.

26 S. Noskov, C. Scherer and M. Maskos, Determination of Hamaker constants of polymeric nanoparticles in organic solvents by asymmetrical flow field-flow fractionation, $J$. Chromatogr. A, 2013, 1274(25), 151-158.

27 L. Bergstrom, Hamaker constants of inorganic materials, Adv. Colloid Interface Sci., 1997, 70, 125-169.

28 C. Gutsche, U. F. Keyser, K. Kegler and F. Kremer, Forces between single pairs of charged colloids in aqueous salt solutions, Phys. Rev. E: Stat., Nonlinear, Soft Matter Phys., 2007, 76, 031403.

29 A. G. Bracamonte, D. Brouard, M. Lessard-Viger, D. Boudreau and A. V. Veglia, Nano-supramolecular complex synthesis: switch on/off enhanced fluorescence control an molecular release using a simple chemistry reaction, Microchem. J., 2016, 128, 297-304.

30 A. V. Veglia and A. G. Bracamonte, Metal enhanced fluorescence emission and quenching protection effect with a host-guest nanophotonic-supramolecular structure, J. Nanophotonics, 2018, 12(3), 033004.

31 A. V. Veglia and A. G. Bracamonte, $\beta$-Cyclodextrin grafted gold nanoparticles with short molecular spacers applied for nanosensors based on plasmonic effects, Microchem. J., 2019, 148, 277-284.

32 J. Zhang, Y. Fu, M. H. Chowdhury and J. R. Lakowicz, Metalenhanced single-molecule fluorescence on silver particle monomer and dimer: coupling effect between metal particles, Nano Lett., 2007, 7(7), 2101-2107.

33 Y. Kuai, J. Chen, X. Tang, Y. Xiang, F. Lu, L. Kuang, L. Xu, W. Shen, J. Cheng, H. Gui, G. Zou, P. Wang, H. Ming, J. Liu, X. Liu, J. R. Lakowicz and D. Zhang, Label-free surface-sensitive photonic microscopy with high spatial resolution using azimuthal rotation illumination, Sci. Adv., 2019, 5, eaav5335.

34 H. Dacres, J. Wang, M. M. Dumancic and S. C. Trowell, Experimental determination of the forster distance for two commonly used bioluminescent resonance energy transfer pairs, Anal. Chem., 2010, 82, 432-435.

35 R. Sjoback, J. Nygren and M. Kubista, Absorption and fluorescence properties of fluorescein, Spectrochim. Acta, Part A, 1995, 51, L7-L21.

36 X. F. Zhang, J. Zhnang and L. Lin, Fluorescence properties of twenty fluorescein derivates: lifetime, quantum yield, 
absorption and emission spectra, J. Fluoresc., 2014, 24, 819826.

37 A. G. Bracamonte, C. I. Salinas and M. V. Ame, Enhanced luminescent nanoplatforms based on FRET, Biophotonics applications, Editorial Académica Española: OmniScriptum GmbH \& Co. KG, 2019, ISBN 978-613-9-44056-6.

38 C. Munkholm, D.-R. Parkinson and D. R. Walt, Intramolecular Fluorescence Self-Quenching of Fluoresceinamine, J. Am. Chem. Soc., 1990, 112, 2608-2612.

39 J. A. B. Ferreira and S. M. B. Costa, Non-radiative learning decay in rhodamines:role of $1: 1$ and $1: 2$ molecular complexation with $\beta$-cyclodextrin, J. Photochem. Photobiol., A, 2005, 173, 309-318.

40 D. Magde, G. E. Rojas and P. Seybold, Solvent Dependence of the Fluorescence Lifetimes of Xanthene Dyes, Photochem. Photobiol., 1999, 70, 737-742.

41 R. Vogel, P. Meredith, M. D. Harvey and H. RubinszteinDunlop, Absorption and fluorescence spectroscopy of rhodamine $6 \mathrm{G}$ in titanium dioxide nanocomposites, Spectrochim. Acta, Part A, 2004, 60(1-2), 245-249.

42 I. Gammoudi, N. Rokhaya Faye, F. Moroté, D. Moynet, C. Grauby-Heywang and T. Cohen-Bouhacina, Characterization of Silica Nanoparticles in Interaction with Escherichia coli Bacteria, International Journal of Chemical, Molecular, Nuclear, Materials and Metallurgical Engineering, 2013, 7(7), 520-526.

43 K. Jiang and P. Pinchuk, Temperature and size-dependent Hamaker constants for metal nanoparticles, Nanotechnology, 2016, 27, 345710.

44 R. De Philippis and M. Vincenzini, Exocellular polysaccharides from cyanobacteria and their possible applications, FEMS Microbiol. Rev., 1998, 22, 151-175.

$45 \mathrm{H}$. Schubert, U. Schiewer and E. Tschirner, Fluorescent characteristics of Cyanobacteria (blue-green algae), $J$. Plankton Res., 1989, 11(2), 353-359.

46 J. M. Lehn, Angew. Chem., Int. Ed. Engl., 1988, 27(1), 89-112.

47 E. V. Anslyn, Supramolecular analytical chemistry, J. Org. Chem., 2007, 72, 687-699.

48 R. M. Silverstein, Spectrometric Identification of Organic Compounds, Wiley Publishing, 2014.

49 M. D. Disney, J. Zheng, T. M. Swager and P. H. Seeberger, Detection of Bacteria with Carbohydrate-Functionalized Fluorescent Polymers, J. Am. Chem. Soc., 2004, 126, 1334313345.

50 D. Gontero, A. V. Veglia, D. Boudreau and A. G. Bracamonte, Ultraluminescent gold core@shell nanoparticles applied to individual bacterial detection based on metal-enhanced fluorescence nanoimaging, J. Nanophotonics, 2018, 12(1), 012505.

51 A. Armaselu, A. Popescu, I. Apostol and I. I. Ardelean, Passive nonspecific labeling of cyanobacteria in natural samples using quantum dots, Optoelectron. Adv. Mater., Rapid Commun., 2011, 5(10), 1084-1090.

52 L. Bruno, F. Di Pippo, S. Antonaroli, A. Gismondi, C. Valentini and P. Albertano, Characterization of biofilm- forming cyanobacteria forbiomass and lipid production, $J$. Appl. Microbiol., 2012, 113, 1052-1064.

53 M. P. Herrling, S. Lackner, O. Tatti, G. Guthausen, M. Delay, M. Franzreb, et al., Short and long term biosorption of silicacoated iron oxide nanoparticles in heterotrophic biofilms, Sci. Total Environ., 2016, 544, 722-729.

54 S. Alizadeh, S. Ghoshal and Y. Comeau, Fate and inhibitory effect of silver nanoparticles in high rate moving bed biofilm reactors, Sci. Total Environ., 2019, 647, 1199-1210.

55 L. Deschênes and T. Ells, Bacteria-nanoparticle interactions in the context of nanofouling, Adv. Colloid Interface Sci., 2020, 277, 102106.

56 I. Ardelean, D. Diaz-Pernil, M. A. Gutierrez-Naranjo, F. PeniaCantillana and I. Sarchizian, Studying the chlorophyll fliorescence in cyanobacteria with membrane computing techniques, Proceedings of the Eleventh Brainstorming Week on Membrane Computing, 2013, pp. 9-23, 978-84-940691-9-2.

57 A. R. Holzwarth, Yearly Review-Fluorescence Lifetimes in Photosynthetic systems, Photochem. Photobiol., 1986, 43(6), 707-725.

58 A. R. Holzwarth, J. Wendler and G. W. Suter, Studies on cromophore coupling in isolated phycobiliproteins, Biophys. J., 1987, 51, 1-12.

59 I. Yamazaki, M. Mimuro, T. Murao, T. Yamazaki, K. Yoshihara and Y. Fujita, Excitation energy transfer in the light harvesting antenna system of the red alga porphyridium cruenturn and the blue-green alga anacystis nidulans: analysis of time-resolved fluoresc- ence spectra, Photochem. Photobiol., 1984, 39, 233-240.

60 S. Meech, Biophotonics, 2011, 5, 387-388.

61 M. C. Gather and S. H. Yun, Single-cell biological lasers, Nat. Photonics, 2011, 5, 406-410.

62 S. Dufour and Y. De Koninck, Optrodes for combined optogenetics and electrophysiology in live animals, Neurophotonics, 2015, 2(3), 031205.

63 C. Tardif, G. Nadeau, S. Labrecque, D. Côté, F. LavoieCardinal and $\mathrm{P}$. De Koninck, Fluorescence lifetime imaging nanoscopy for measuring Förster resonance energy transfer in cellular nanodomains, Neurophoton, 2019, 6(1), 015002.

64 C. Liu and C. E. Capjack, Effects of cellular fine structure on scattered light pattern, IEEE Transactions on NanoBioscience, 2006, 5(2), 76-82.

65 P. Lin, R. Owens, G. Tricot and C. S. Wilson, Flow Cytometric Immunophenotypic Analysis of 306 Cases of Multiple Myeloma, Am. J. Clin. Pathol., 2004, 121, 482-488.

66 C. Salinas and A. G. Bracamonte, From Microfluidics to Nanofluidics and signal Wave-guiding for Nanophotonics, Biophotonics resolution and Drug Delivery, Frontiers in Drug, Chemistry and Clinical Research, 2019, 2, 1-6.

67 C. Salinas and G. Bracamonte, Design of Advanced Smart Ultraluminescent Multifunctional Nanoplatforms for Biophotonics and Nanomedicine Applications, Frontiers in Drug, Chemistry and Clinical Research, 2018, 1(1), 1-8. 